\title{
Cyclone Wind Retrieval Based on X-Band SAR-Derived Wave Parameter Estimation
}

\author{
Weizeng Shao, ${ }^{\mathrm{a}, \mathrm{d}}$ Yuyi Hu, ${ }^{\mathrm{a}}$ Ferdinando NunZiata, ${ }^{\mathrm{b}}$ VAleria CORCiOne, ${ }^{\mathrm{b}}$ Maurizio MigliaCCIO, ${ }^{\mathrm{b}}$ And \\ XIAOMING LI ${ }^{\mathrm{c}}$ \\ ${ }^{\mathrm{a}}$ Marine Science and Technology College, Zhejiang Ocean University, Zhoushan, China; ${ }^{\mathrm{b}}$ Electromagnetic Fields, Università degli \\ Studi di Napoli Parthenope, Naples, Italy; ${ }^{\mathrm{c}}$ Aerospace Information Research Institute, Chinese Academy of Science, Beijing, China; \\ ${ }^{\mathrm{d}}$ National Satellite Ocean Application Service, Beijing, China
}

(Manuscript received 3 February 2020, in final form 7 August 2020)

\begin{abstract}
In this study, a method for retrieving wind speed from synthetic aperture radar (SAR) imagery collected under extreme weather conditions is proposed. The rationale for this approach relies on the fact that, although copolarized channels exhibit saturation for wind speed $>\sim 20 \mathrm{~m} \mathrm{~s}^{-1}$, the wave growth can be successfully exploited to gather information on wind speed under extreme weather conditions. Hence, in this study, the intrinsic relationship among the wind-wave triplets [wind speed at $10 \mathrm{~m}$ above the sea surface, significant wave height $(\mathrm{SWH})$, and peak wave period] is exploited in order to retrieve wind speeds under tropical cyclone conditions. Experiments, undertaken on actual X-band TerraSAR-X (TS- $X$ ) SAR images of tropical cyclones (Typhoon Megi, Hurricane Sandy, and Hurricane Miriam) and using collocated WAVEWATCH-III (WW3) simulations, revealed the robustness of the proposed approach, which resulted in a root-meansquare error (RMSE) of $2.54 \mathrm{~m} \mathrm{~s}^{-1}$ when comparing the retrieved wind speeds with the values from products delivered by the National Oceanic and Atmospheric Administration (NOAA) Hurricane Research Division (HRD). However, the applicability of the algorithm herein will be further confirmed at very strong storms.
\end{abstract}

KEYWORDS: Sea state; Tropical cyclones; Wind; Algorithms; Remote sensing

\section{Introduction}

Tropical cyclones are considered to be among the most dangerous and destructive natural phenomena in the world, both in terms of economic impact and loss of human life. Hence, the monitoring of such destructive phenomena is of paramount importance. Within this context, imaging radars operated on board Earth observation satellites play a key role in collecting tropical cyclone data since they represent one of the safest methods for synoptically monitoring such phenomena.

In this work, the German TerraSAR-X (TS-X) mission was utilized. This satellite is equipped with an $X$-band $(9.8 \mathrm{GHz})$ synthetic aperture radar (SAR) sensor, which is an efficient instrument for monitoring the sea surface. The $T S-X$ is characterized by adequate signal-to-noise ratio (SNR), with a noise-equivalent sigma zero (NESZ) ranging from -19 to $-26 \mathrm{~dB}$ (Buckreuss and Schattler 2010). Hence, the TS- $X$ SAR provides fine spatial resolution and highquality imagery (up to $1 \mathrm{~m}$ ), resulting in a suitable instrument for sea observation purposes, e.g., wind speed and direction, waves, and so on, especially when monitoring hurricanes and typhoons.

In the literature, several studies have proposed achieving sea surface wind speed retrieval using $T S-X$ data collected in vertical-vertical (VV) (Diaz Méndez et al. 2010; Thompson et al. 2012) and horizontal-horizontal (HH) polarization under moderate wind regimes (Shao et al. 2014, 2016). These studies were based on the theoretical rationale that sea surface wind speed can be retrieved by exploiting a geophysical model function (GMF), i.e., an empirical function

Corresponding author: Weizeng Shao, shaoweizeng@mail. tsinghua.edu.cn linking the wind speed with the normalized radar cross section (NRCS), the wind direction and the incidence angle. Notable examples of this GMF are the X-band GMF (XMOD) and the C-band GMF (CMOD). The well-known linear XMOD1 (Ren et al. 2012) and the Shuttle Imaging Radar (SIR)-XMOD (Ren et al. 2015), which is based on the CMOD-IFR2 formula (Quilfen et al. 1998), are similar to the CMOD4 (Stoffelen and Anderson 1997), CMOD5/5.N (Hersbach et al. 2007; Hersbach 2010), and CMOD7 (Stoffelen et al. 2017). The coefficients are tuned using the SIR X-band SAR VV-polarization data and wind data, provided by the German Weather Service (DWD) and the European Centre for Medium-Range Weather Forecasts (ECMWF), for wind speeds $<25 \mathrm{~m} \mathrm{~s}^{-1}$. Recently, using available datasets collected from DWD numerical model wind vectors, a nonlinear XMOD2 (Li and Lehner 2014; Corcione et al. 2018) was developed and validated against in situ buoy measurements, yielding retrieved wind speeds with a bias of $-0.32 \mathrm{~m} \mathrm{~s}^{-1}$ and an RMSE of $1.44 \mathrm{~m} \mathrm{~s}^{-1}$. When dealing with high wind regimes, the GMF approach cannot be applied in a straightforward manner since copolarized channels exhibit saturation (Hwang et al. 2010a,b; Voronovich and Zavorotny 2014), resulting in unreliable sea surface wind speed retrieval. Although the NRCS values for cross-polarized channels do not seem to be affected by saturation problems, even for wind speeds up to $45 \mathrm{~m} \mathrm{~s}^{-1}$ (van Zadelhoff et al. 2014), these channels are not always available since they are not routinely collected, e.g., cross-polarized data unavailable for $T S-X$.

In this study, a robust empirical wind-wave growth relationship is considered to estimate wind speed under extreme weather conditions using copolarized SAR measurements. The wind-wave triplets [sea surface wind speed at $10 \mathrm{~m}$ height $U_{10}$, significant wave height (SWH) $H_{s}$, and peak wave period $T_{p}$ ] are closely related to each other and all can be computed from 


\section{Normalized Radar Cross Section (dB)}

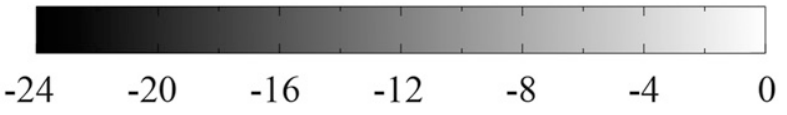

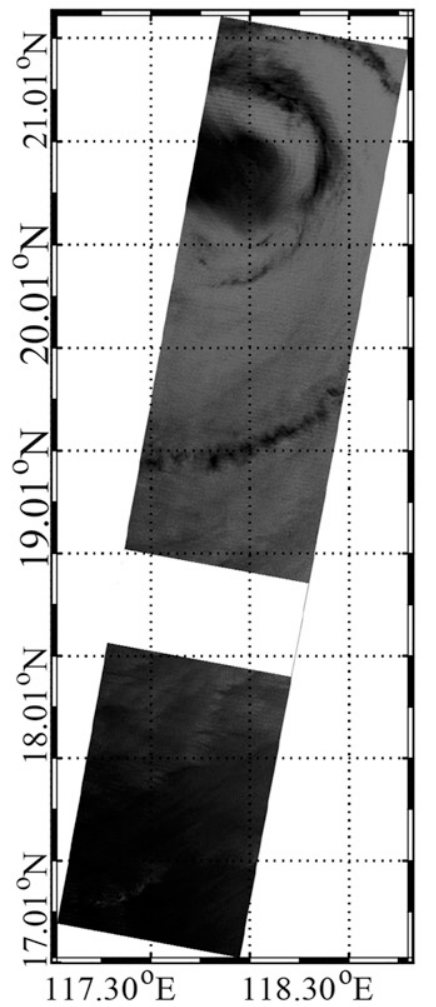

(a)

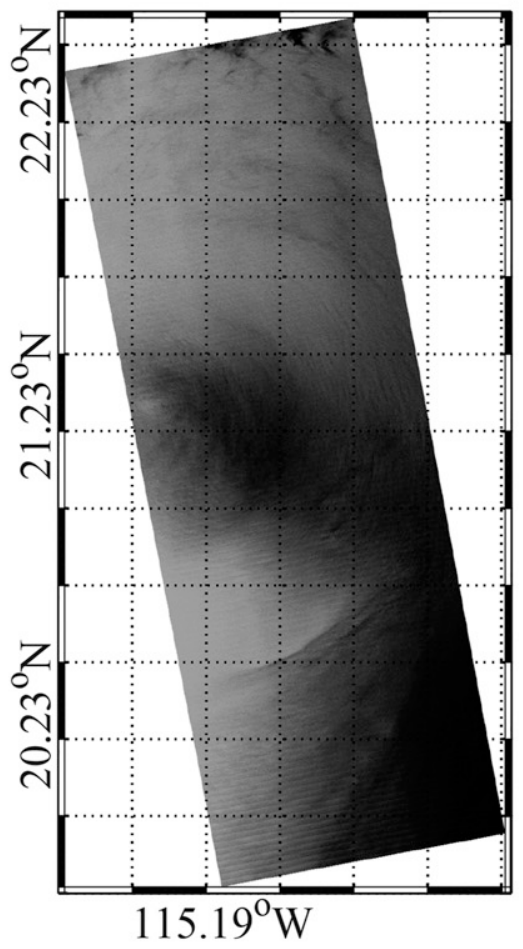

(b)

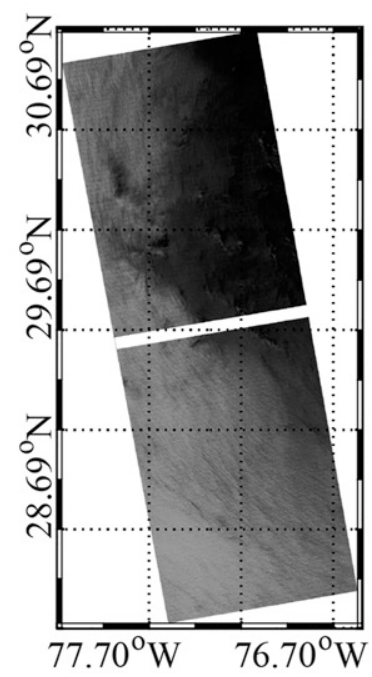

(d)

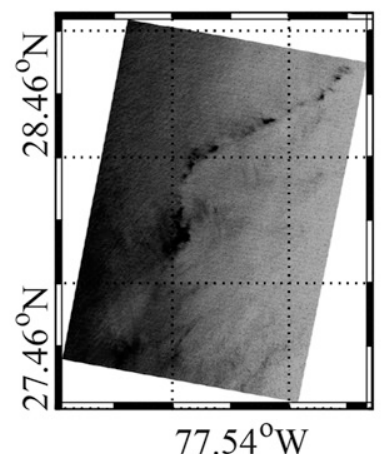

(c)

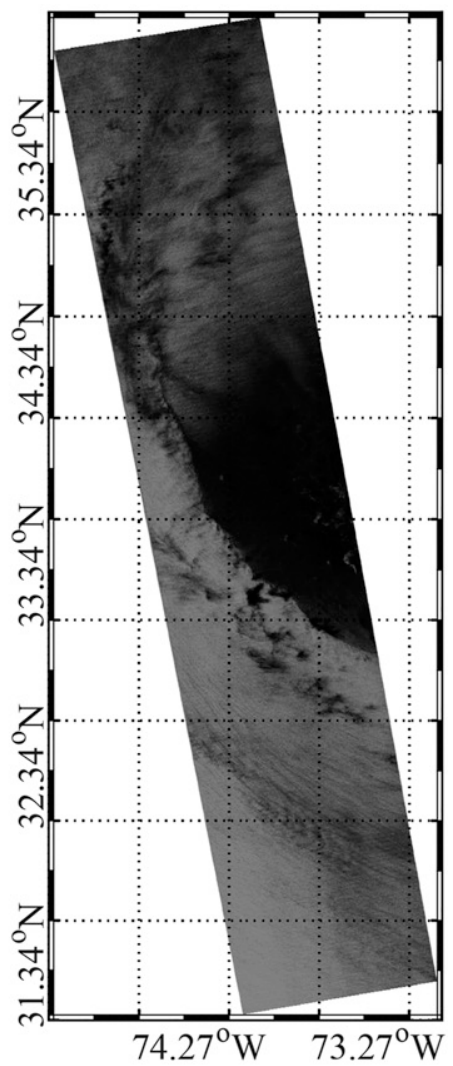

(e)

FIG. 1. Quick-look images of four TerraSAR-X (TS-X) SAR images in VV polarization: (a) image of Typhoon Megi acquired in ScanSAR (SC) mode at 2206 UTC 21 Oct 2010; (b) image of Hurricane Miriam acquired in SC mode at 0139 UTC 27 Sep 2012;(c) image of Hurricane Sandy acquired in SC mode at 1116 UTC 26 Oct 2012; (d) image of Hurricane Sandy acquired in SC mode at 2306 UTC 27 Oct 2012; and (e) image of Hurricane Sandy acquired in SC mode at 2249 UTC 28 Oct 2012. 
TABLE 1. Information on concerning the MGD VV-polarized TerraSAR-X $(T S-X)$ images in Typhoon Megi and Hurricane Sandy imaging mode: ScanSAR pixel size azimuth $\times$ range: $8.25 \mathrm{~m} \times 8.25 \mathrm{~m}$

\begin{tabular}{lllccrr}
\hline \hline Cyclone name & \multicolumn{1}{c}{ Acquisition time } & \multicolumn{1}{c}{ Cyclone eye } & $\begin{array}{c}\text { Incidence } \\
\text { angle }\left(^{\circ}\right)\end{array}$ & $\begin{array}{c}\text { Maximum wind } \\
\text { speed }\left(\mathrm{m} \mathrm{s}^{-1}\right)\end{array}$ & $\begin{array}{c}\text { Saffir- } \\
\text { Pressure }(\mathrm{hPa})\end{array}$ & Simpson scale \\
\hline Megi & $2206: 06$ UTC 21 Oct 2010 & $20.7^{\circ} \mathrm{N}, 118.3^{\circ} \mathrm{E}$ & $29.7-38.3$ & 50.0 & 935 & 2 \\
Miriam & 0139:30 UTC 27 Sep 2012 & $21.2^{\circ} \mathrm{N}, 115.6^{\circ} \mathrm{W}$ & $22.6-32.5$ & 23.1 & 997 & 1 \\
Sandy & $1116: 43$ UTC 26 Oct 2012 & $26.4^{\circ} \mathrm{N}, 76.9^{\circ} \mathrm{W}$ & $19.7-30.0$ & 33.5 & 970 & 1 \\
& $2306: 10$ UTC 27 Oct 2012 & $30.3^{\circ} \mathrm{N}, 75.1^{\circ} \mathrm{W}$ & $34.1-42.2$ & 33.5 & 960 & 1 \\
& $2250: 20$ UTC 28 Oct 2012 & $33.6^{\circ} \mathrm{N}, 71.2^{\circ} \mathrm{W}$ & $31.8-40.5$ & 36.0 & 950 & 1 \\
\hline
\end{tabular}

knowledge of any one of the three due to the fetch-limited wave-growth features within hurricanes and typhoons (Hwang and Wang 2004; Hwang 2006, 2016). Hence, utilizing the wave information $\left(H_{s}\right.$ or $\left.T_{p}\right)$ to derive wind speed is an opportunity to obtain the high wind speed from the X-band SAR data in cyclonic conditions. Recent studies (Bruck and Lehner 2013, 2015; Shao et al. 2015) have shown that X-band ocean wave retrieval algorithms, either using the empirical XWAVE or the theoretically based parameterized first-guess spectrum method (PFSM), achieve a scatter index (SI) of wave height $H_{s}$ equal to $20 \%$ against other measurements. In the literature, the relationship between the WAVEWATCH-III (WW3)-simulated
SWH and the SAR-derived parameters, e.g., VV-polarization NRCS $\sigma_{0}^{\mathrm{vv}}$ in decibels (dB), the variance of the NRCS (cvar), and the azimuth cutoff wavelength $\lambda_{c}$ (Corcione et al. 2019) normalized by the satellite range-to-velocity parameter $\beta$, has been analyzed using several dual-polarization Sentinel-1 (S-1) SAR images collected of hurricanes (Shao et al. 2018a). Hence, a wave retrieval approach based on the well-known CWAVE model, which is designed to be an empirical function relating the sea state parameter SWH with a set of variables derived from SAR intensity, has been adopted for S-1 SAR measurements under cyclone conditions and has been successfully verified. The advantage of the CWAVE model is that

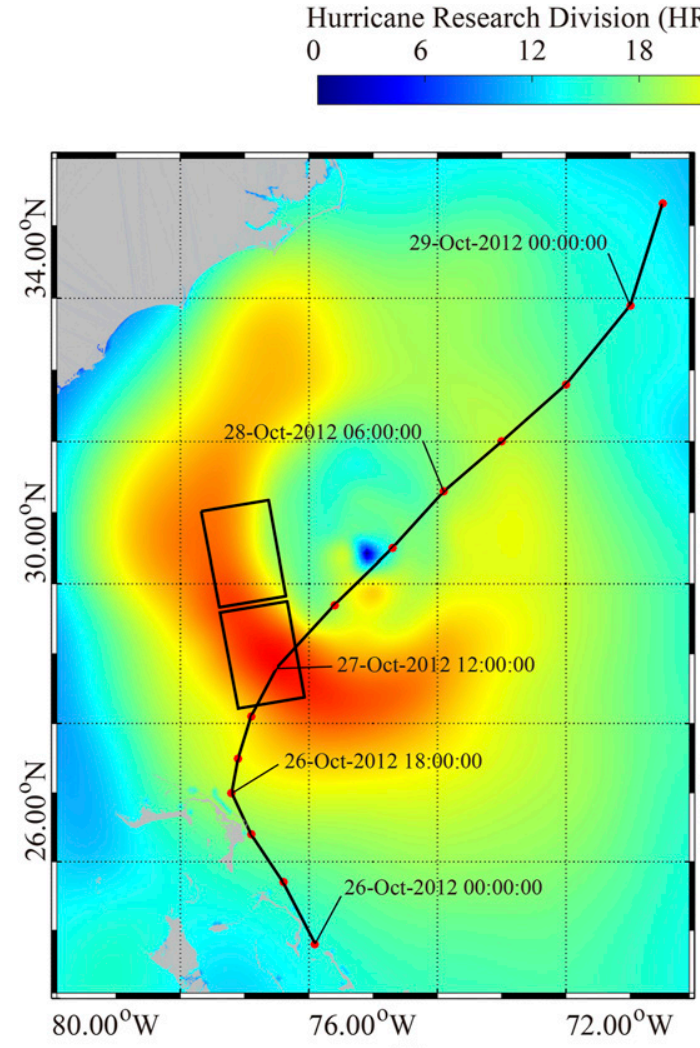

(a)

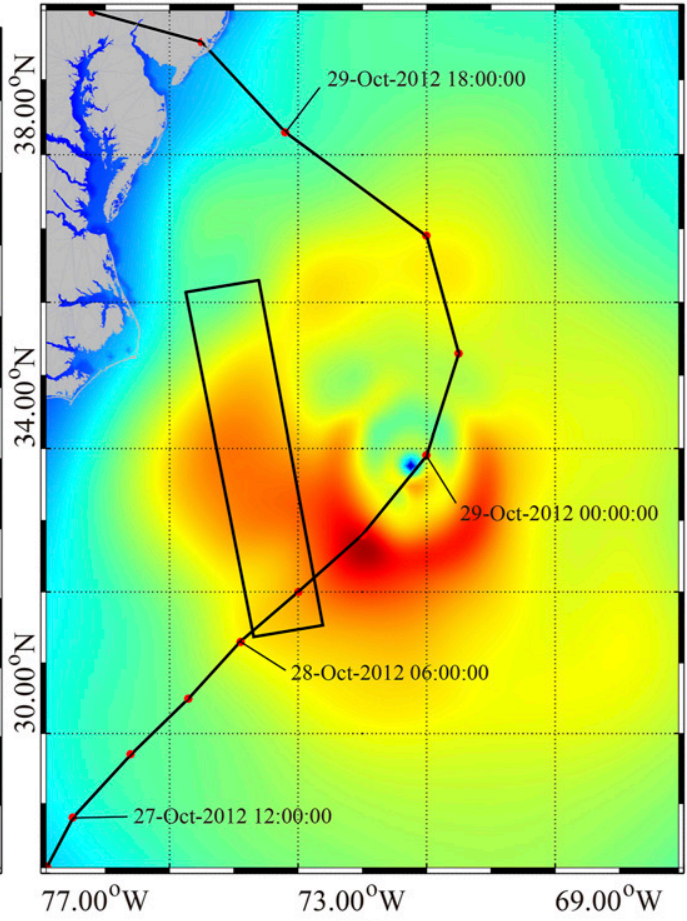

(b)

FIG. 2. Hurricane Research Division (HRD) winds at (a) 2200 UTC 27 Oct and (b) 2300 UTC 28 Oct 2012. Black rectangle represents the coverage of $T S$ - $X$ images and the track of Hurricane is provided by National Oceanic and Atmospheric Administration (NOAA) National Hurricane Center (NHC). 


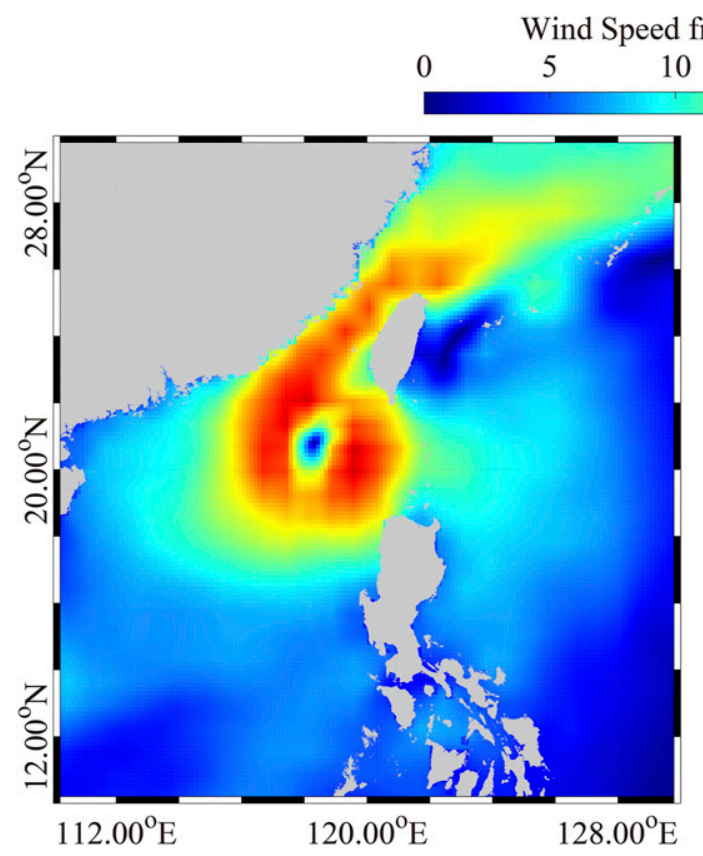

(a)

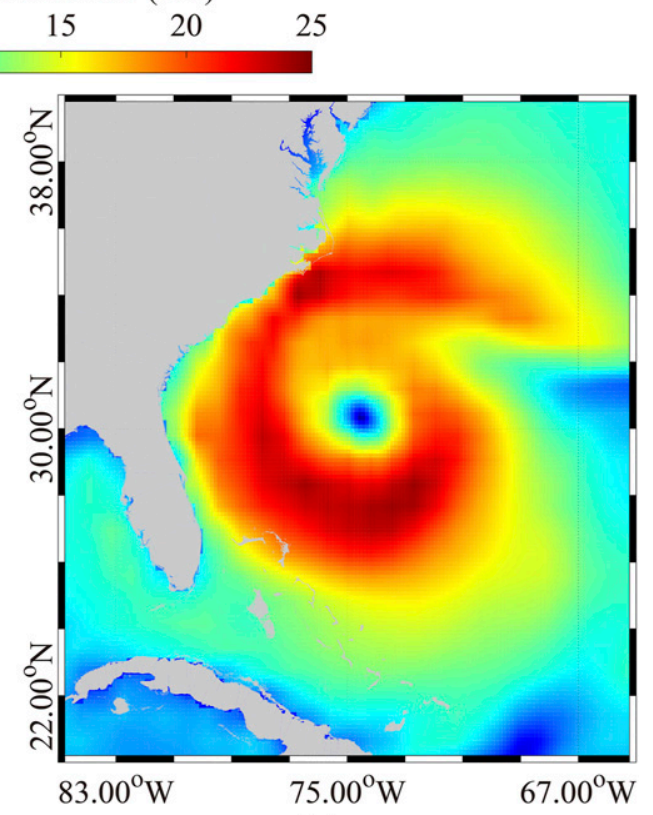

(b)

FIG. 3. European Centre for Medium-Range Weather Forecasts (ECMWF) wind fields. (a) Typhoon Megi wind field at 0000 UTC 22 Oct 2010. (b) Hurricane Sandy wind field at 0000 UTC 28 Oct 2012.

SWH can be directly retrieved from SAR without calculating the modulation transfer function (MTF) of each SAR mapping modulation (Alpers et al. 1981; Alpers and Bruning 1986). However, the CWAVE model needs to be retuned before applying it to various C-band SAR data. Following the CWAVE concept, the XWAVE empirical algorithms for X-band SAR (Bruck and Lehner 2013, 2015) have been well developed for wave retrieval of the low-tomoderate sea state.

It is still challenging, however, to retrieve significant wave height $H_{s}$ under extreme weather conditions. Within this context, it is relatively easy to estimate $T_{p}$ using the SAR image spectra with a method that exploits the wave peak length (Romeiser et al. 2015) and a deep-water wave dispersion relation, under the hypothesis that the hurricane or typhoon is moving toward the open sea. This method, although very useful for exploiting the large availability of C-band SAR products routinely collected under extreme weather conditions by the European Sentinel-1 constellation and the Canadian RADARSAT-2 mission (Shao et al. 2017b), cannot be exploited to deal with the X-band data collected by the $T S-X$ and COSMO-SkyMed missions.

In this study, a robust empirical wind retrieval approach is proposed that is based on 1) an empirical algorithm for retrieving SWH $H_{s}$ that exploits the CWAVE, e.g., CWAVE_ERS (Schulz-Stellenfleth et al. 2007), CWAVE_ENVI (Li et al. 2011) and CWAVE_S1 (Stopa et al. 2015) and XWAVE (Pleskachevsky et al. 2016; Shao et al. 2017a) models applied to $T S-X$ images collected under cyclonic conditions; and 2) the intrinsic relationship among wind-wave triplets (Hwang et al. 2017). This proposed approach, tested on $T S-X$ images of Typhoon Megi (21 October 2010) and Hurricane Sandy (26-28 October 2012) using collocated WW3 simulations, yielded a wind speed root-mean-square error of $2.54 \mathrm{~m} \mathrm{~s}^{-1}$. Besides, an additional $T S-X$ image taken in Hurricane Miriam (27 September 2012) is also used to validate the SAR-derived winds against the retrieved results using GMF XMOD2 due to there being no available HRD data matchup with this image.

The remainder of this manuscript is organized as follows: $T S$ - $X$ SAR images, collected under extreme weather conditions, as well as other auxiliary data used in this study are described in section 2; the methodology for retrieving SWH $H_{s}$ and wind speed $U_{10}$ from the SAR images of tropical cyclones is introduced in section 3; the validation of the SAR-derived SWH and the accuracy of the retrieved high winds via a comparison with National Oceanic and Atmospheric Administration (NOAA) Hurricane Research Division (HRD) wind vectors and the retrieval results using GMF XMOD2 are presented in section 4; the discussion is in section 5; and section 6 comprises our conclusions and summary.

\section{Description of datasets}

\section{a. SAR data}

In this study, four multilook ground range detected (MGD) VV-polarized $T S$ - $X$ ScanSAR SAR images were used: one image was acquired over Typhoon Megi on 21 October 2010, three images were acquired of Hurricane Sandy from 26 to 28 October 2012, and one image acquired of Hurricane Miriam on 27 September 2012, each with a swath width of 


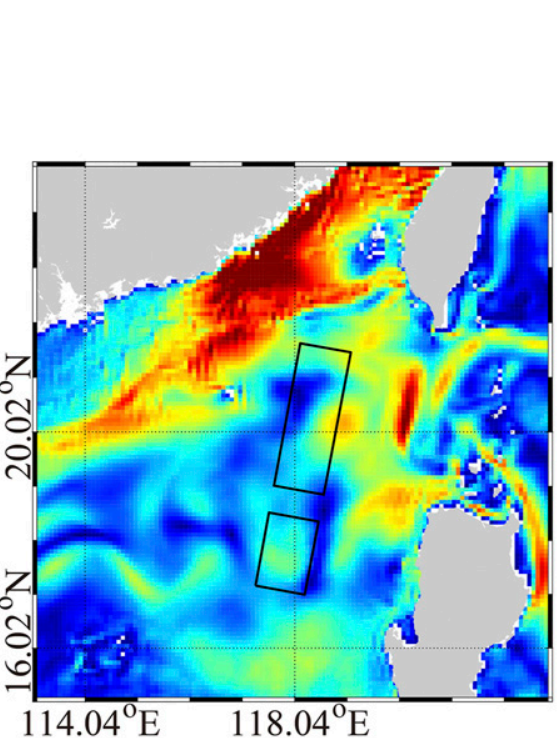

(a)

\section{Current Speed (m/s)}

0 0.5 1 1.5

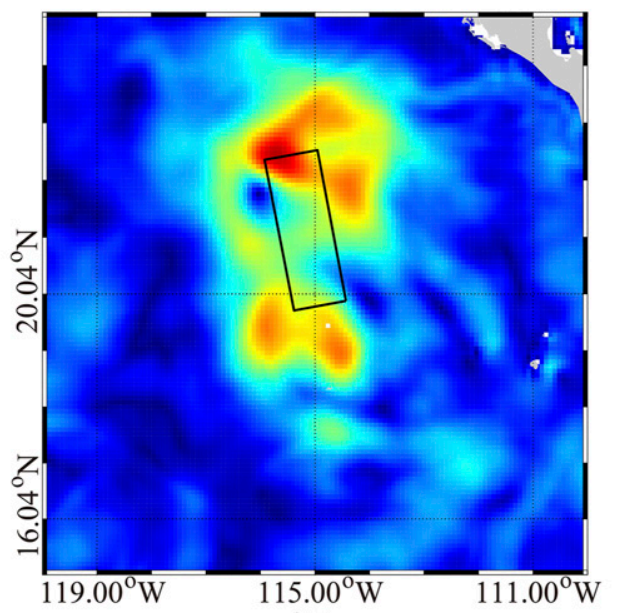

(b)

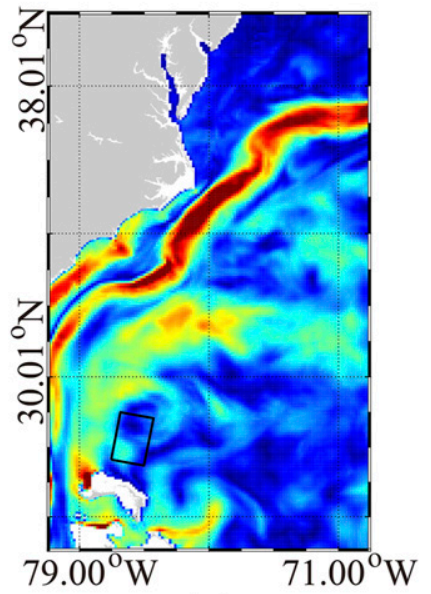

(c)

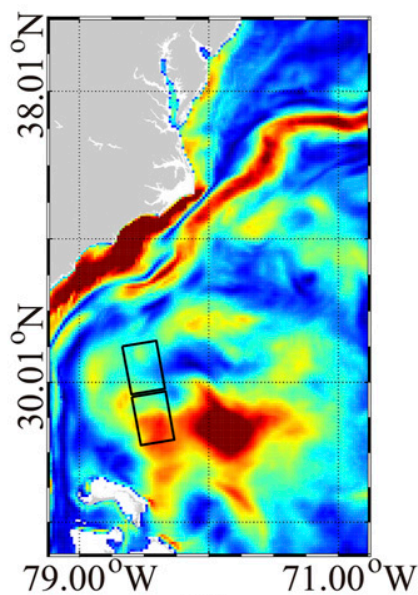

(d)

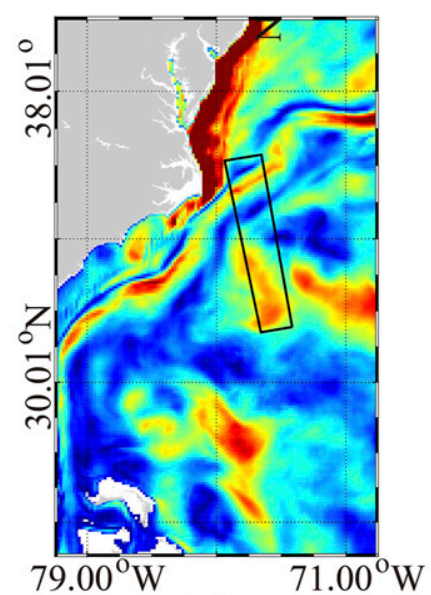

(e)

FIG. 4. Sea surface current speed field from the Hybrid Coordinate Ocean Model (HYCOM) model, in which the black rectangles delineate the coverage of TS-X images: (a) 0000 UTC 22 Oct 2010, (b) 0300 UTC 27 Sep 2012, (c) 1200 UTC 26 Oct 2012, (d) 0000 UTC 28 Oct 2012, and (e) 0000 UTC 29 Oct 2012.

$100 \mathrm{~km}$ and a pixel size of $8.25 \times 8.25 \mathrm{~m}^{2}$. All of the images are shown in Fig. 1 and all of the information concerning the three cyclones is listed in Table 1.

\section{b. HRD wind data}

Look-alike line patterns are often observed in SAR images, phenomena that are referred to as wind streaks. It has been revealed that homogeneous wind streaks follow the wind direction, which can be extracted by calculating twodimensional SAR image spectra for wavelengths between 800 and $3000 \mathrm{~m}$ (Shao et al. 2015). The rain cells in typhoons and hurricanes usually distort the SAR intensity spectra, however, thereby affecting the backscattering signal and rendering the wind streaks invisible. Fortunately, the wind streaks were clearly visible on 27 and 28 October 2012 for
Hurricane Sandy, and nearly collocated NOAA HRD winds were available, which were assimilated with ground observations (buoys, ships), aircraft observations, and various satellite measurements. The nearly simultaneous NOAA HRD wind maps with an interval of $1 \mathrm{~h}$ and a spatial resolution of approximately $10 \times 10 \mathrm{~km}^{2}$, are shown in Fig. 2 . The areas covered by the $T S-X$ images are enclosed by the black rectangles. In addition, the track of Hurricane Sandy was kindly provided by National Hurricane Center (NHC) from NOAA.

\section{c. WW3-simulated SWH}

Since it is quite difficult to obtain wave measurements when examining cyclones, the third-generation numerical wave model WW3 (version 5.16) developed by the National 
Significant Wave Height (SWH) from WAVEWATCH-III (WW3) (m)

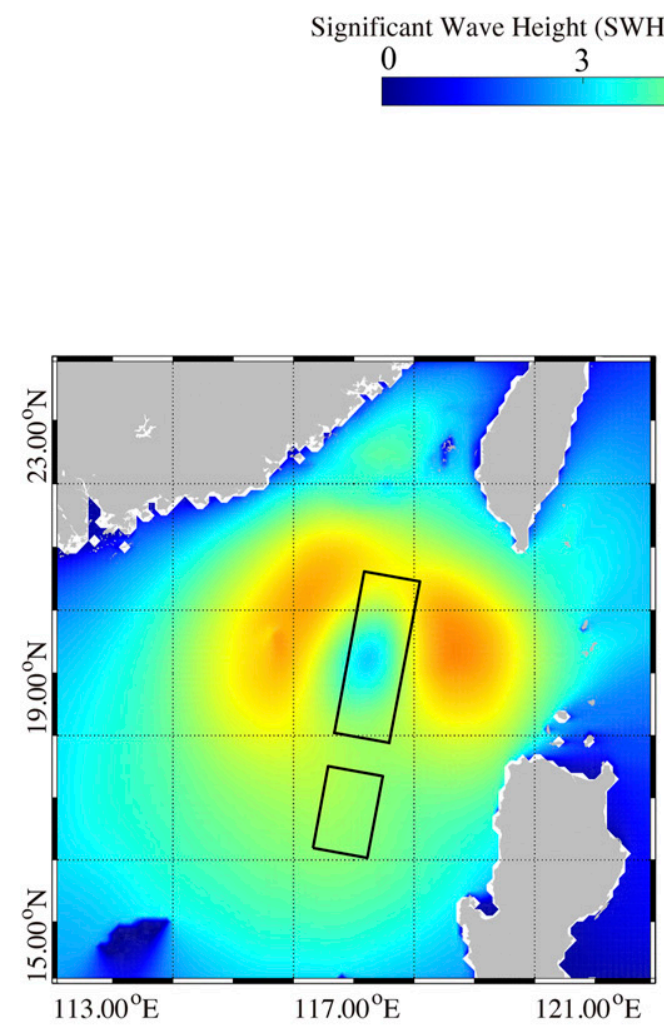

(a)

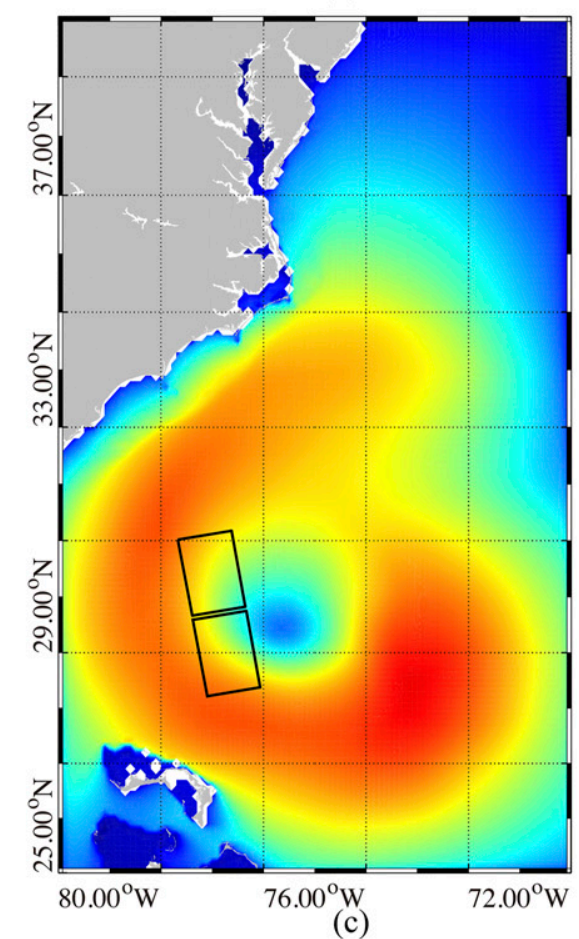

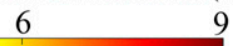

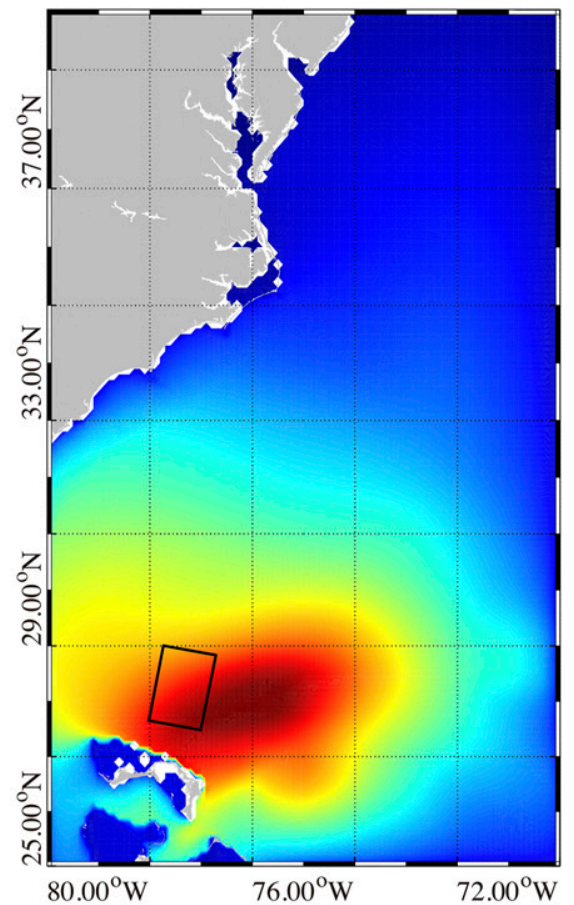

(b)

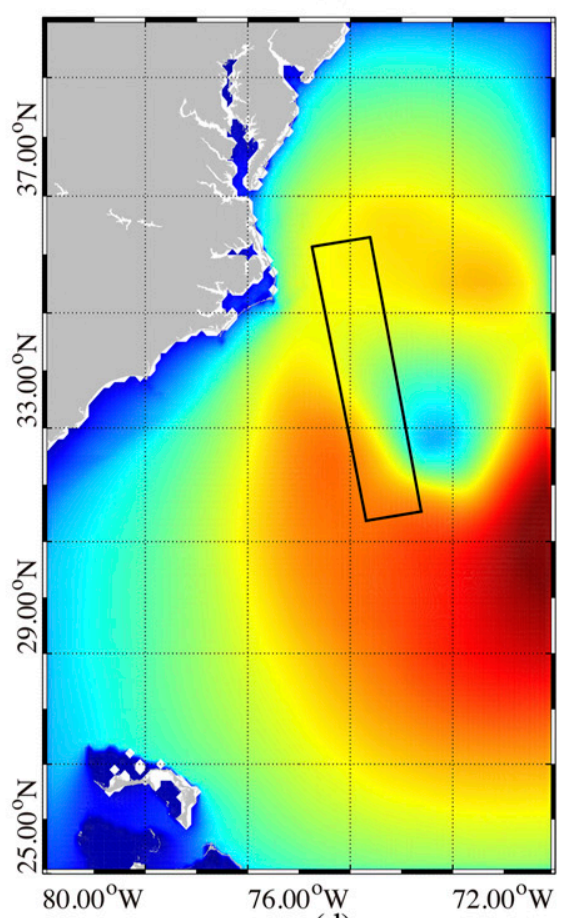

(d)

FIG. 5. Simulated wave field from the WW3 model, in which the black rectangles delineate the coverage of TS-X images: (a) 2200 UTC 21 Oct 2010, (b) 2230 UTC 26 Oct 2012, (c) 2230 UTC 27 Oct 2012, and (d) 2230 UTC 28 Oct 2012. 


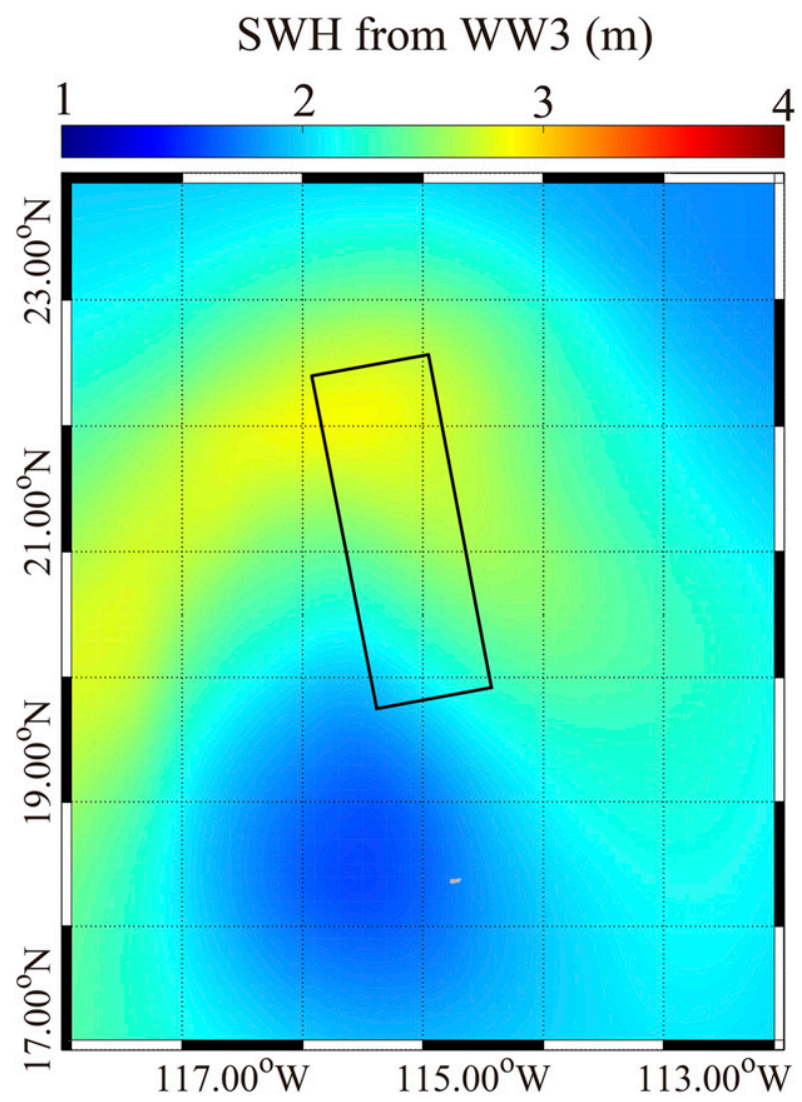

FIG. 6. Simulated wave field from the WW3 model, in which the black rectangles delineate the coverage of $T S-X$ images at 0139 UTC 27 Sep 2012.

Centers for Environmental Prediction (NCEP) of NOAA was used to simulate the sea surface wave fields (Mondon and Warner 2009; Zheng et al. 2016; Shao et al. 2018b; Sheng et al. 2019). The winds were provided by the ECMWF, which has continuously, delivered global gridded atmosphere-marine reanalysis data with a fine resolution, as precise as a $0.125^{\circ}$ grid, at intervals of $6 \mathrm{~h}$ each day since 1979. The maps of ECMWF wind fields of Typhoon Megi at 0000 UTC 22 October 2010 and Hurricane Sandy at 0000 UTC 28 October 2012 are shown in Fig. 3. Topography data were provided by the General Bathymetric Chart of the Oceans (GEBCO) from the British Oceanographic Data Centre (BODC). At present, sea surface current data from Hybrid Coordinate Ocean Model (HYCOM) are open accessed. The current speed fields from the HYCOM model are shown in Fig. 4, in which the black rectangles represent the spatial coverages of $T S-X$ images. The WW3 simulations were obtained using the following settings:

- the two-dimensional wave spectrum was resolved into 24 regular azimuthal directions with a $15^{\circ}$ step;

- the frequency bins ranged logarithmically between 0.04118 and 0.7186 at an interval of $\Delta f / f=0.1$;

- the spatial propagation was characterized by $300 \mathrm{~s}$ time steps in both the longitudinal and latitudinal directions;

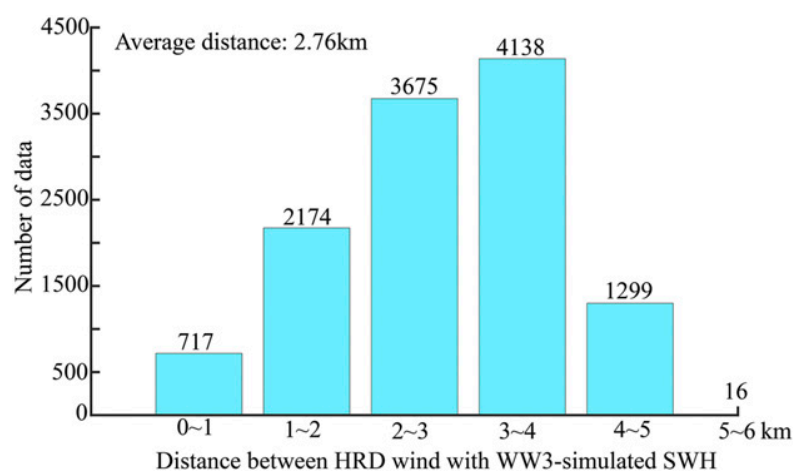

FIG. 7. The distance between HRD wind with WW3simulated SWH.

- the spatial resolution of the simulated wave fields was a $0.2^{\circ}$ grid with a $30 \mathrm{~min}$ temporal resolution;

- the input/dissipation terms are selected, referred to as ST2 and STAB2 (Sheng et al. 2019);

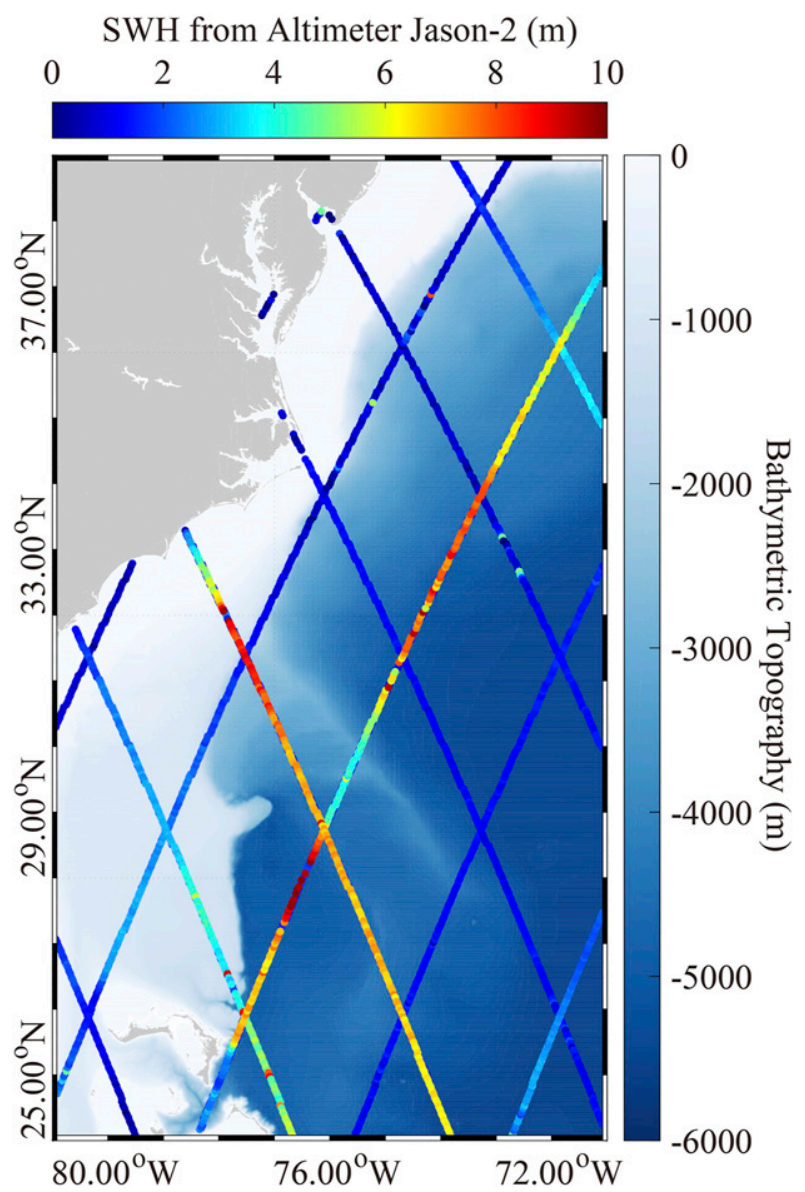

FIG. 8. Footprints of altimeter Jason-2 from 15 Aug to 31 Oct 2012 are available for Hurricane Sandy, which are overlaid on the water depth map. 


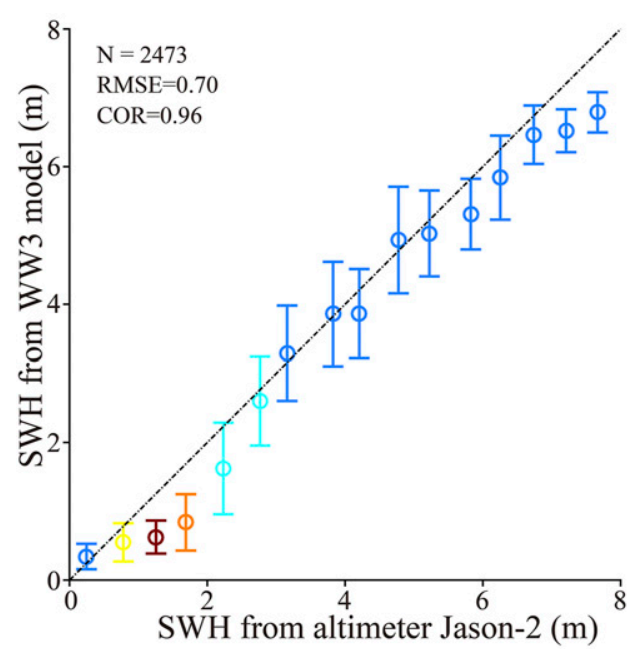

(a)

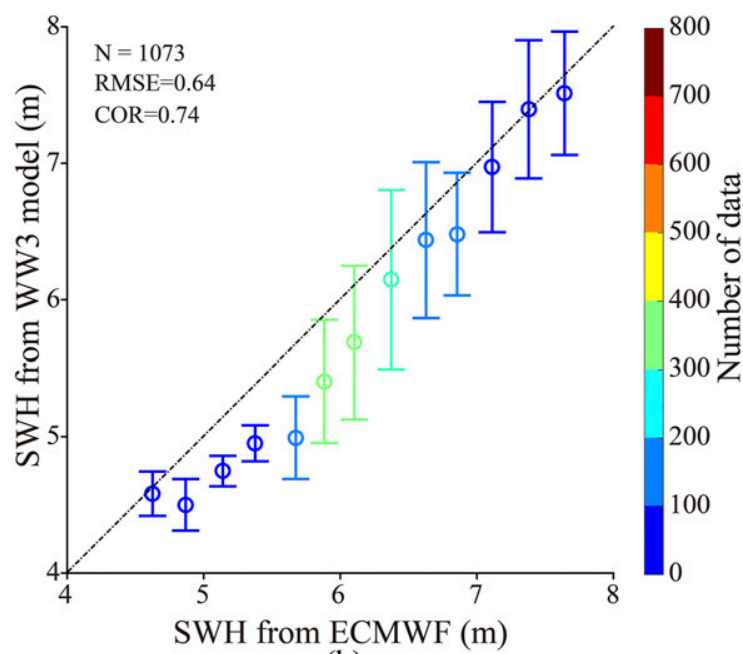

(b)

FIG. 9. (a) WW3-simulated SWHs against collocated measurements from altimeter Jason-2 for a 0.4 bin of SWH. (b) WW3-simulated SWH for collected SAR images contrasted with collocated ECMWF SWH for a 0.2 bin of SWH. The error bars represent the standard deviation of each bin.

- the generalized multiple discrete interaction approximation (GMD) package of the nonlinear term for quadruplets wave-wave interactions is used (Shao et al. 2018b).

As a matter of fact, wave-current interactions (WCI) are assumed be simultaneously included in the wave simulation; therefore, we initially taken the WCI term into the simulation process using HYCOM current field. However, it was found that the simulated SWH with WCI is slightly different from the results without WCI for the collected $T S$ - $X$ images. Referred to the results in conclusion of our recent study $(\mathrm{Hu}$ et al. 2020), the current has the increasing influence on wave when the current speed greater than $0.5 \mathrm{~m} \mathrm{~s}^{-1}$. As for those five $T S$ - $X$ images, current speed is up to $1.5 \mathrm{~m} \mathrm{~s}^{-1}$, in particular, current speed is smaller than $0.5 \mathrm{~m} \mathrm{~s}^{-1}$ for $T S-X$ image on 27 October 2012 in Hurricane Sandy. Under this circumstance, the simulations without WCI term is directly used for this study.

Although the maximum wind speed of the cyclones during the SAR acquisition was approximately $36 \mathrm{~m} \mathrm{~s}^{-1}$, the SWH calls for values $<9 \mathrm{~m}$, as shown in Fig. 5. Figure 6 shows the simulated SWH map for the case in Hurricane Miriam, in which maximum SWH reaches $3 \mathrm{~m}$. The distance between the HRD wind and the WW3-simulated SWH is shown in the Fig. 7, indicating the average distance is $2.76 \mathrm{~km}$.

\section{d. Altimeter Jason-2 wave data}

Altimeter data are typically used for global wave distribution analysis (Liu et al. 2016). In this study, some measurements obtained by the altimeter Jason-2 during the 2 cyclones were utilized to evaluate the accuracy of the WW3 simulations. Unfortunately, the altimeter Jason-2 data are available covering the SAR images during the Hurricane Sandy. Moreover, the time difference between altimeter Jason-2 data and the $T S-X$ images during the Hurricane
Sandy is more than $16 \mathrm{~h}$, indicating the SAR-derived SWH could not be validated against the measurements from altimeter Jason-2. In Fig. 8, the footprints of altimeter Jason-2 spanning the period 15 August-31 October 2012 and collocated with Hurricane Sandy are overlaid on the water depth map. In Fig. 9a, the WW3-simulated SWH are contrasted with the collocated measurements collected by altimeter Jason-2. The resulting RMSE was $0.70 \mathrm{~m}$. To further investigate the accuracy of the simulation SWH, a comparison with the ECMWF was also conducted, as shown in Fig. 9b, in which the SWH simulated by the WW3 are contrasted with the SWH provided by the ECMWF. In this case, an adequate RMSE $(0.64 \mathrm{~m})$ was obtained, confirming the robustness of the WW3-simulated wave approach.

\section{Methodology}

In this section, the data processing sequence is briefly introduced, and the methodology utilized to retrieve the wind speed under extreme weather conditions is then described.

\section{a. Data processing}

The first step consists of calibrating the $T S$ - $X$ dataset according the TS-X user manual (Buckreuss and Schattler 2010), stated as follows:

$$
\sigma^{0}=F \times \mathrm{DN}^{2} \times \sin \theta,
$$

where $\sigma^{0}$ is the linear NRCS, DN is the digital number, $F$ is the calibration constant, and $\theta$ is the incidence angle.

The second step consists of partitioning the $T S-X$ images into subimages of $512 \times 512$ pixels, corresponding to $4 \times 4 \mathrm{~km}^{2}$, covering a periodic wave propagation. The nonlinear effects induced by SAR velocity bunching (Hasselmann and Hasselmann 1991) are more pronounced under the undetectable short waves. In addition, the presence of rain cells also affects the 


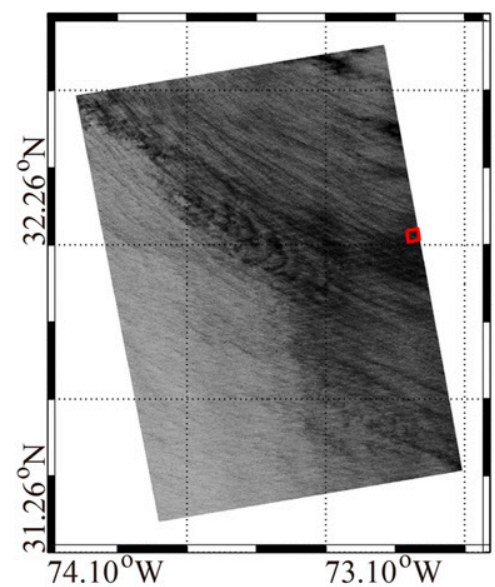

(a)

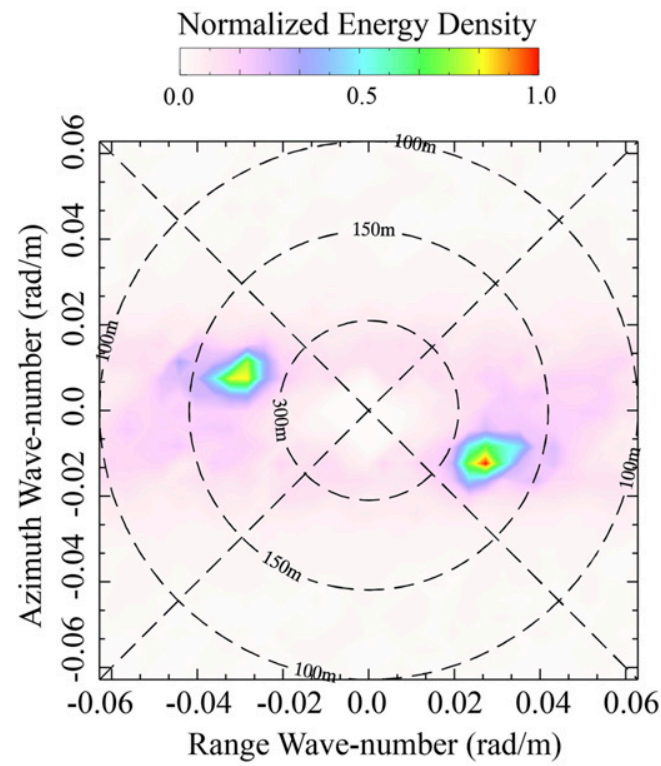

(c)

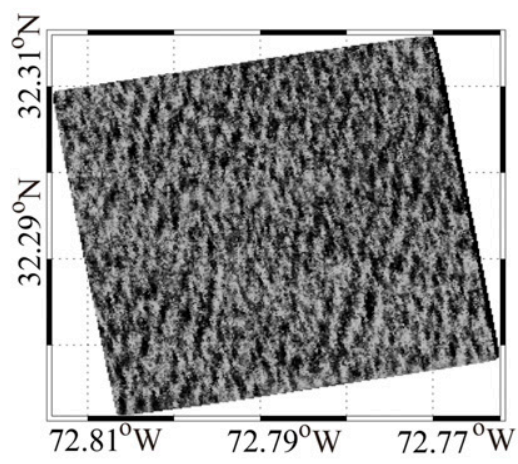

(b)

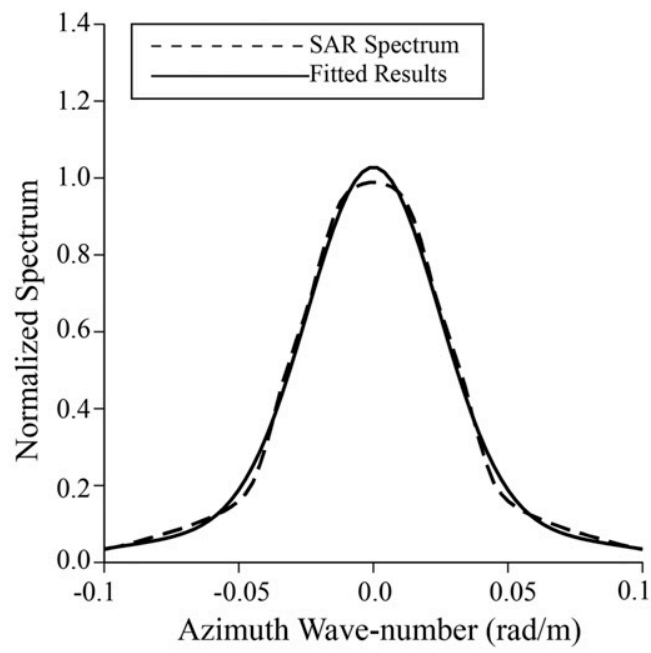

(d)

FIG. 10. Meaningful example used to clarify the proposed processing steps: (a) the TS-X SAR quick-look image, in which the red rectangles delineate the spatial coverage of selected subimage; (b) the subimage extracted from (a); (c) two-dimensional SAR spectrum; (d) Gaussian fit.

SAR backscattering signature. Hence, the inhomogeneous subimages that would call for poor-quality SAR intensity spectra were excluded. The exclusion role is based on the ratio of image variance and the squared image mean (cvar), with the threshold set to 1.05 (Li et al. 2011). For each subimage resulting in cvar $<1.05$, the SAR image spectrum is computed. Then the azimuth cutoff wavelength $\lambda_{c}$, the integrated energy $E_{s}\left[=\int_{0}^{2 \pi} \int_{k_{\min }}^{k_{\max }} \bar{S}(k, \theta) d k d \theta\right]$ of the derived wavenumber spectrum $\bar{S}(k, \theta)$ with corresponding limits $L_{\min }=2 \pi / k_{\min }=30 \mathrm{~m}$ to $L_{\max } 2 \pi / k_{\max }=600 \mathrm{~m}$ (Bruck and Lehner 2013), and direction for a given range $\varphi$ are extracted.

As an example, a subimage extracted from the SAR image collected at 2230 UTC 28 October 2012 and the corresponding two-dimensional SAR spectrum are shown in
Figs. $10 \mathrm{~b}$ and $10 \mathrm{c}$, respectively. The corresponding $T S-X$ SAR image linking to the subimage is shown in Fig. 10a. To estimate the azimuth cutoff wavelength, the one-dimensional SAR spectrum was fitted with a Gaussian function, whose mathematical formula is of the type $\exp \left[\pi\left(k_{x} / k_{c}\right)\right]$ with $k_{x}$ being the azimuthal wavenumber and $k_{c}$ being the azimuthal cutoff wavenumber $\left(=2 \pi / \lambda_{c}\right)$ (Stopa et al. 2015; Shao et al. 2017a). The Gaussian fitted result corresponding to the subimage in Fig. 10b is illustrated in Fig. 10d.

\section{b. SWH retrieval algorithm}

In this study, the CWAVE model, which is well-known when dealing with C-band SAR imagery, was exploited in order to design a wave algorithm for $T S$ - $X$ data, which allows the 
TABLE 2. Constants used in parametric fetch in the Fourier expansion.

\begin{tabular}{ccccc}
\hline \hline$Q$ & $S_{\eta x}$ & $I_{\eta x}$ & $S_{\omega x}$ & $I_{\omega x}$ \\
\hline$a_{0 q}$ & & & & $-7.88 \times 10^{-4}$ \\
$p_{1}$ & $-1.40 \times 10^{-2}$ & $1.95 \times 10^{0}$ & $3.22 \times 10^{0}$ & $-1.42 \times 10^{2}$ \\
$p_{2}$ & $1.57 \times 10^{0}$ & $-3.54 \times 10^{1}$ & $3.27 \times 10^{0}$ & \\
$a_{1 q}$ & & & $1.09 \times 10^{0}$ \\
$p_{1}$ & $-1.02 \times 10^{-2}$ & $1.26 \times 10^{0}$ & $-1.34 \times 10^{-2}$ & $-5.22 \times 10^{1}$ \\
$p_{2}$ & $5.10 \times 10^{-1}$ & $-4.77 \times 10^{1}$ & $9.85 \times 10^{-1}$ & $1.16 \times 10^{0}$ \\
$b_{1 q}$ & & & $-1.02 \times 10^{2}$ \\
$p_{1}$ & $5.21 \times 10^{-3}$ & $-8.23 \times 10^{-1}$ & $-1.27 \times 10^{-2}$ & $-1.10 \times 10^{0}$ \\
$p_{2}$ & $-6.87 \times 10^{-2}$ & $3.02 \times 10^{1}$ & $1.51 \times 10^{0}$ & $6.93 \times 10^{1}$ \\
$a_{2 q}$ & & & \\
$p_{1}$ & $5.55 \times 10^{-3}$ & $-4.11 \times 10^{-1}$ & $-1.23 \times 10^{-2}$ & $1.51 \times 10^{0}$ \\
$p_{2}$ & $-4.79 \times 10^{-1}$ & $2.25 \times 10^{1}$ & & $-9.80 \times 10^{1}$ \\
$b_{2 q}$ & & $-2.00 \times 10^{-2}$ & \\
$p_{1}$ & $-3.32 \times 10^{-3}$ & $-1.52 \times 10^{-1}$ & & \\
$p_{2}$ & $2.11 \times 10^{-1}$ & $8.86 \times 10^{0}$ & & $-26 \times 10^{0}$ \\
$a_{3 q}$ & & & $1.45 \times 10^{-2}$ & $-1.52 \times 10^{-1}$ \\
$p_{1}$ & $6.44 \times 10^{-3}$ & $-5.32 \times 10^{-1}$ & \\
$p_{2}$ & $-3.29 \times 10^{-1}$ & $2.85 \times 10^{1}$ & & $1.01 \times 10^{0}$ \\
$b_{3 q}$ & & & $-8.47 \times 10^{-1}$ & $-4.71 \times 10^{1}$ \\
$p_{1}$ & $1.91 \times 10^{-3}$ & $-2.28 \times 10^{-1}$ & $1.80 \times 10^{-1}$ & \\
$p_{2}$ & $-2.25 \times 10^{-1}$ & $2.11 \times 10^{1}$ & & \\
\hline
\end{tabular}

retrieval of the SWH from a set of SAR-based parameters $S_{i}$ $(i=1, \ldots, n)$ once the coefficients $A_{i, j}(i \leq j \leq n)$ have been tuned by taking into account the nonlinearity of SAR-based parameters:

$$
H_{s}=A_{0}+\sum_{i=1}^{n} A_{i} S_{i}+\sum_{i, j=1}^{n} A_{i, j} S_{i} S_{j} .
$$

It is suggested to select an $\mathbf{S}$ vector that consists of the following SAR-derived parameters, which are related to the SWH. In this study, we interpolated the WW3-simulated SWH intervals and HRD winds to SAR imaging data using a cubic spline interpolation in a temporal scale. The entire $T S-X$ dataset was collocated with the simulations obtained by the WW3 model and the $T S-X$ images acquired on 2728 October 2012 were collocated with the HRD winds. Totally, more than 2500 matches with the simulated SWHs from the WW3 model (which were used for wave retrieval purposes) including two cases: image of Typhoon Megi acquired at 2205 UTC 21 October 2010 and image of Hurricane Sandy acquired at 2223 UTC 26 October 2012, and 1000 matches with the HRD wind speeds for validating the retrieval of strong winds were available from image of Hurricane Sandy acquired at 2223 UTC 27 October 2012 and image of Hurricane Sandy acquired at 2249 UTC 28 October 2012. The matched dataset was used to tune the $A$ coefficients using the least squares method. For the purposes of this study, $n=6$ and the subscripts $(1, \ldots, 6)$ represent the corresponding $S_{i}$ variables are $\sigma_{0}^{v v}$, cvar, $\sin \theta$, $\cos \varphi, E_{s}$, and $\lambda_{c} / \beta$. As an example, $A_{23}$ is the coefficient for the term cvar $\times \sin \theta$. Here, the retuned CWAVE model is denoted as XWAVE_TC.

\section{c. Strong wind retrieval algorithm}

According to wave theory, it is well known that wave development under steady wind forcing follows the fetchlimited or duration-limited growth functions (Young 1998; Badulin et al. 2007). In addition, recent studies have also revealed that waves generated by tropical cyclone wind fields adhere to the same relationship connecting dimensionless wave variance and wave frequency (Young 2006). In the study proposed in reference (Hwang 2016), the parametric formulas among the wind-wave triplets were obtained using an airborne scanning radar altimeter measurement:

$$
\begin{aligned}
& U_{10}=397.46 H_{s}^{0.841} x_{\eta x}^{-0.341}, \\
& U_{10}=91.49 T_{p}^{1.900} x_{\omega x}^{-0.450},
\end{aligned}
$$

where $x_{\eta x}$ and $x_{\omega x}$ are the fetch parameters which rely on the radial distance between the SAR samples and the cyclone's eye and the fetch equations are derived for the separate sectors, e.g., right and left with respect to the cyclone's path. The value of $U_{10}$ can be conveniently calculated from the values of $H_{s}$ and $T_{p}$. In particular, a recent study (Romeiser et al. 2015) proposed a technique for obtaining $T_{p}$ from C-band Envisat-ASAR and RADARSAT-1 SAR image spectra estimated using imagery collected under tropical cyclone conditions. Hence, in our previous work, the $T_{p}$-based 


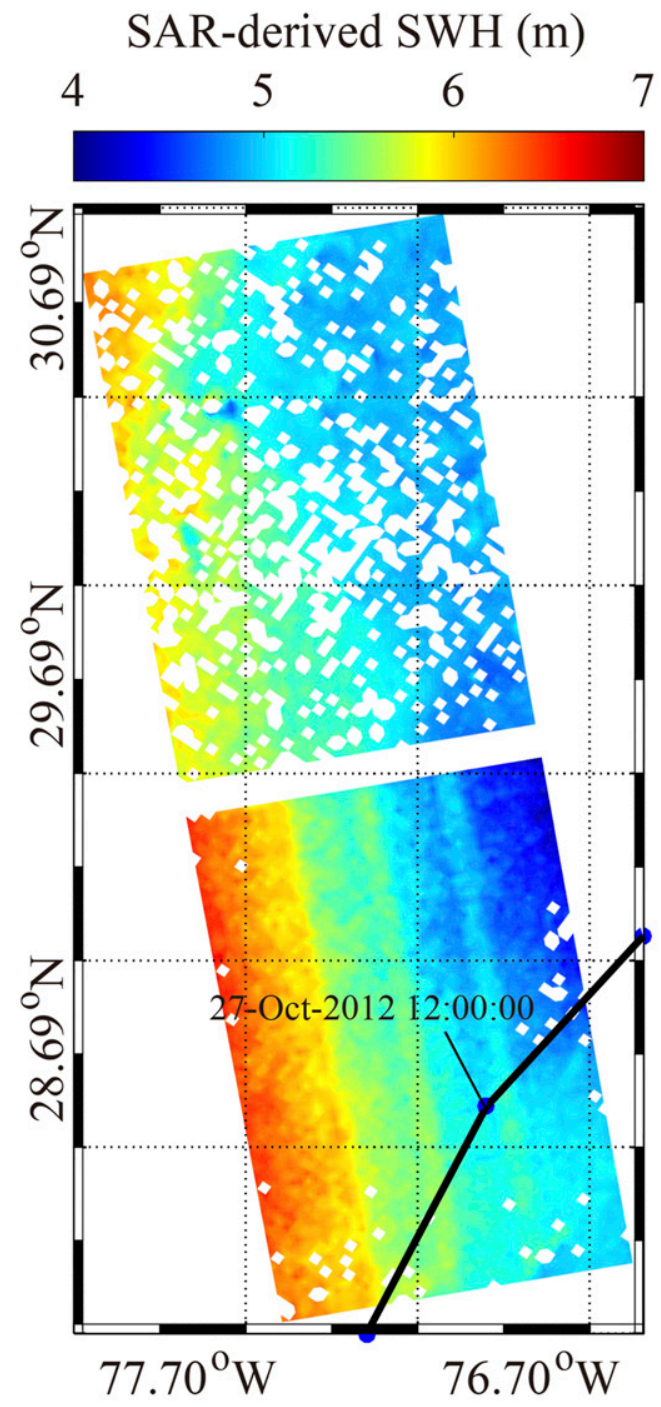

(a)
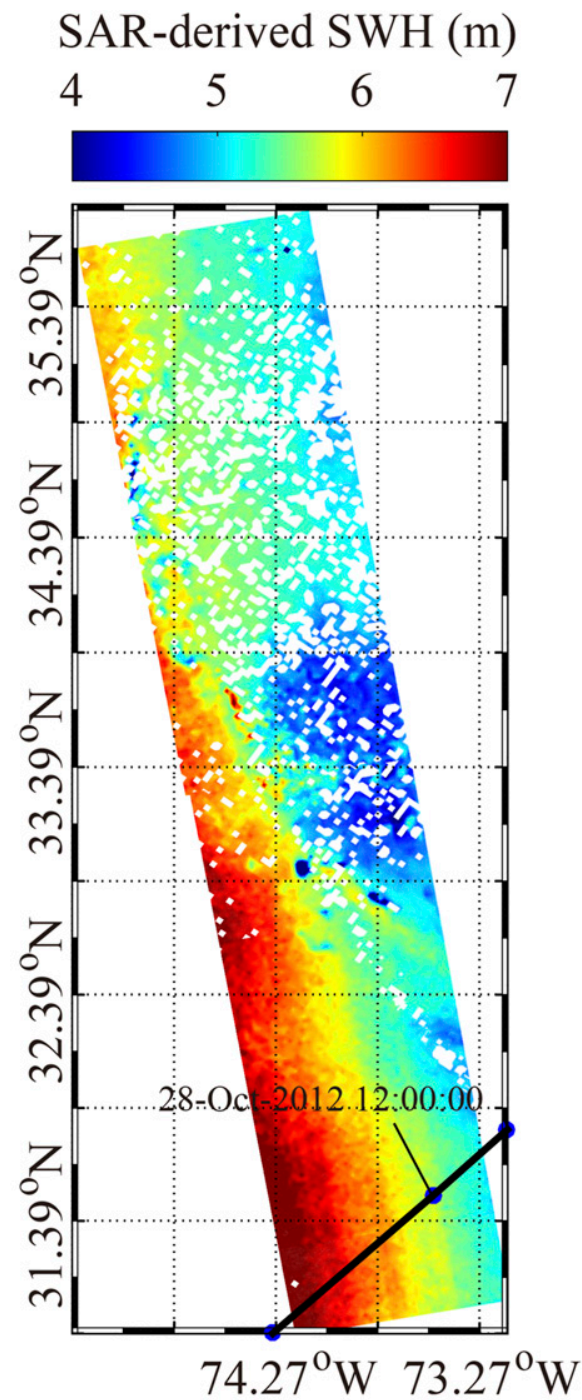

(b)

FIG. 11. SAR-simulated SWH map of Hurricane Sandy at (a) 2223 UTC 27 Oct and (b) 2249 UTC 28 Oct 2012. Black lines represent the track of Hurricane is provided by NOAA NHC.

approach was used to derive the wind speeds within the storm using $6 \mathrm{~S}-1$ and 10 RADARSAT-2 $(R-2)$ images (Shao et al. 2017b) due to the algorithm for SWH retrieval from C-band SAR image was not well studied, resulting in an $\mathrm{RMSE}$ of $2.9 \mathrm{~m} \mathrm{~s}^{-1}$ when the retrieved winds were compared with the NOAA Stepped-Frequency Micro-wave Radiometer (SFMR) measurements. In this study, the SWH-based approach was initially adopted for $\mathrm{X}$-band SAR.

The fetch $x_{\eta x}$ and $x_{\omega x}$ parameterizations (Hwang et al. 2017) were available for continuous hurricane wind fields and the updated scheme was tested on two SAR images of hurricanes, demonstrating good agreement with the reference wind speeds provided by hurricane hunter measurements. The fetch $x_{\eta x}$ and $x_{\omega x}$ can be represented by linear functions of the radial distance $r$ from the hurricane center,

$$
\begin{aligned}
& x_{\eta x}=S_{\eta x}(\phi) r+I_{\eta x}(\phi), \\
& x_{\omega x}=S_{\omega x}(\phi) r+I_{\omega x}(\phi),
\end{aligned}
$$

where $\phi$ is the azimuth angle under the assumption that the hurricane movement heading is set to be positive counterclockwise. The intercept $I$ and slope $S$ are expressed as the Fourier expansion,

$$
Q=a_{0}+2 \sum_{n=1}^{3}\left(a_{n q} \cos n \phi+b_{n q} \sin n \phi\right),
$$

in which $Q$ represents the $S_{\eta x}, I_{\eta x}, S_{\omega x}$, and $I_{\omega x}$. The coefficients $a_{n q}$ and $b_{n q}$ represent the systematic quasi-linear variations as a function of the maximal wind speed radius $r_{m}$,

$$
Y=p_{1 Y} r_{m}+p_{1 Y}
$$




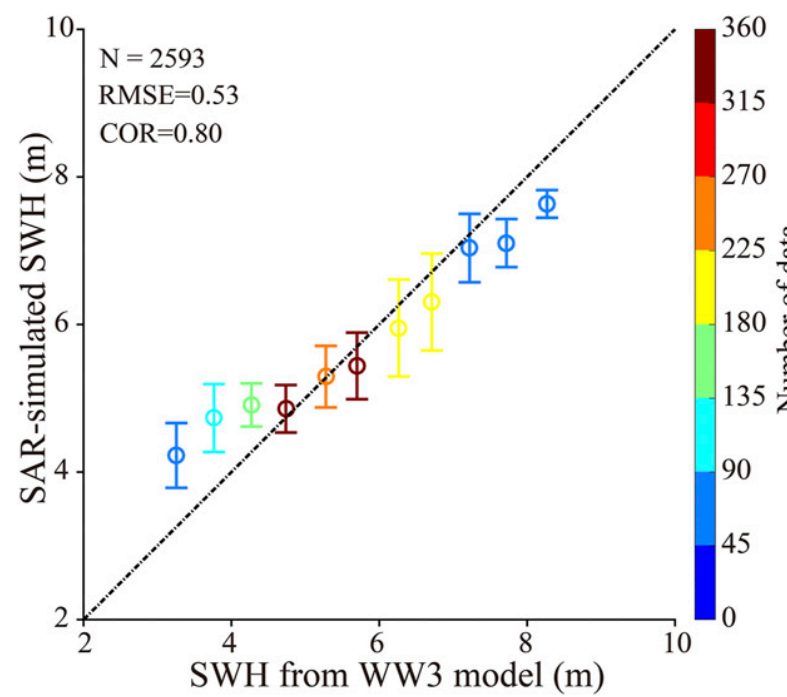

FIG. 12. SAR-simulated SWH using Eq. (2) contrasted with collocated measurements from the WW3 model.

in which $Y$ represents $a_{n q}$ and $b_{n q}$. The values of all the constants are listed in Table 2.

\section{Validation}

In this section, the retuned algorithm is applied to the $T S-X$ dataset and the accuracy of the SWH is discussed. In addition, the retrieved wind speeds are also validated against the NOAA HRD winds.

\section{a. Applicability of the SWH retrieval algorithm}

The SAR-derived SWH maps of Hurricane Sandy on 27 and 28 October 2012 with the typhoon tracks are shown in Figs. 11a and 11b, respectively. One can see that the wave patterns over the entire images are generally consistent with those simulated by the WW3 model, as shown in Fig. 5. It can also be seen noted that there are holes and gaps in the retrieved SWH that are due to the exclusion of subimages from the analysis as a result of the cvar $>1.05$. However, it is also observed that distinct stripes appear at the edges of subswaths. This phenomenon is probably reflecting the different noise floor of each subswath at the incidence angle range, although this type of noise-effect is weak at copolarization channel and the NESZ information is usually excluded in the calibration process, as shown in Fig. 1. This kind of behavior needs to be further studied.

The XWAVE_TC model of Eq. (2) was applied to the matches with the simulated SWH from the WW3 model and results are shown in Fig. 12, in which the retrieved SWH values are plotted against the WW3 simulations. The wave breaking usually appears at the high sea state $\left(H_{s}>7 \mathrm{~m}\right)$ where is mainly dominated by wind sea, which could reduce the variable $E_{s}$ used in XWAVE_TC and may cause the underestimation of SAR-derived SWH. Moreover, XWAVE_TC has the performance of overestimation at the sea state $H_{s}<4 \mathrm{~m}$ where nonlocal swell supposedly dominates especially for the regions near the cyclone center. In other words, the unique SAR wave

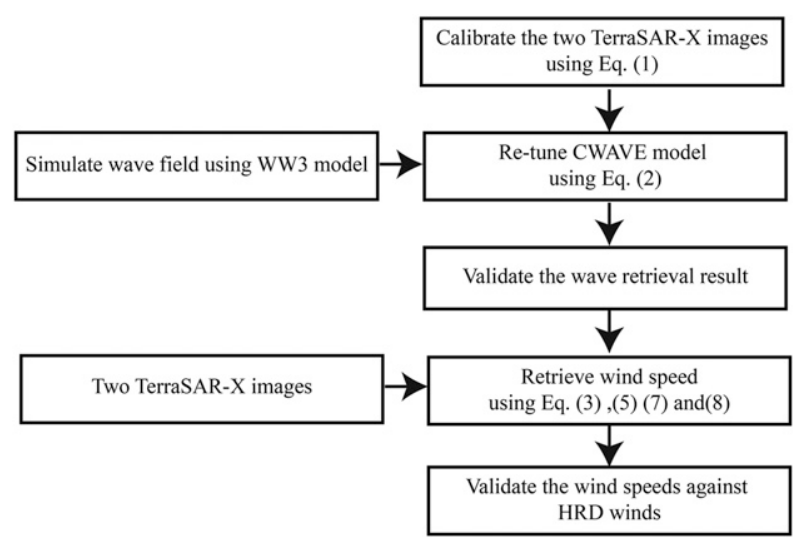

FIG. 13. Flowchart of the proposed strong wind retrieval algorithm for $T S-X$ data.

mapping mechanism "velocity bunching" becomes relatively weak at low sea state; therefore, we think this kind of behavior leads to the larger deviation of SAR-derived SWH. The retrieved SWH values are in good agreement with the simulations, with a correlation (COR) of 0.80 and an RMSE of $0.53 \mathrm{~m}$. These results agree with those of the PFSM (Shao et al. 2015) and XWAVE algorithms (Bruck and Lehner 2013, 2015), which exhibited a similar accuracy of approximately $0.5 \mathrm{~m}$ RMSE obtained using observations from moored buoys or altimeters under light-to-moderate sea states. This implies that the retuned SWH retrieval scheme is suitable for $\mathrm{VV}$-polarized $T S-X$ data under tropical cyclone conditions.

\section{b. Sea surface winds retrieval against HRD winds}

Since only the SWH is calculated from $T S-X$ images, the fetch-limited growth function of SWH in Eq. (3) was employed to retrieve the wind speed. We also give the flowchart of the proposed wind retrieval algorithm, shown in Fig. 13. In this section, the sea surface winds are retrieved and compared with respect to the reference measurements. As a case study, the subimage at $32.29^{\circ} \mathrm{N}, 72.79^{\circ} \mathrm{W}$ was compared to the HRD grid at $32.29^{\circ} \mathrm{N}, 72.76^{\circ} \mathrm{W}$. The $\mathrm{SWH}$ estimated from the subimage of the SAR image and the image simulated using WW3 were 5 and $4.7 \mathrm{~m}$, respectively. Hence, the SAR-derived wind speed $U_{10}$ was $28.6 \mathrm{~m} \mathrm{~s}^{-1}$ which was close to the HRD $U_{10}$ of $28.4 \mathrm{~m} \mathrm{~s}^{-1}$, resulting in a bias of $0.2 \mathrm{~m} \mathrm{~s}^{-1}$. The processing was then applied to the entire $T S-X$ image. The retrieval wind maps on 27 and 28 October 2012 are depicted in Figs. 14a and 14b. Although the patterns of the retrieved winds do not correlate well with HRD winds due the time differences between SAR imaging and HRD moments, those patterns are consistent with the distributions of the $T S-X$ image. Furthermore, the retrieval wind maps for the case Hurricane Miriam by the proposed method and GMF XMOD2 are also shown in the Fig. 15. Again, there are apparent bands at the edge of several subswaths.

In Fig. 16a, the wind speeds retrieved using the SAR images collected on 27 and 28 October were contrasted with the HRD 


\section{SAR-derived Wind Speed $(\mathrm{m} / \mathrm{s})$ \\ 2123252729313335}

\section{SAR-derived Wind Speed $(\mathrm{m} / \mathrm{s})$}

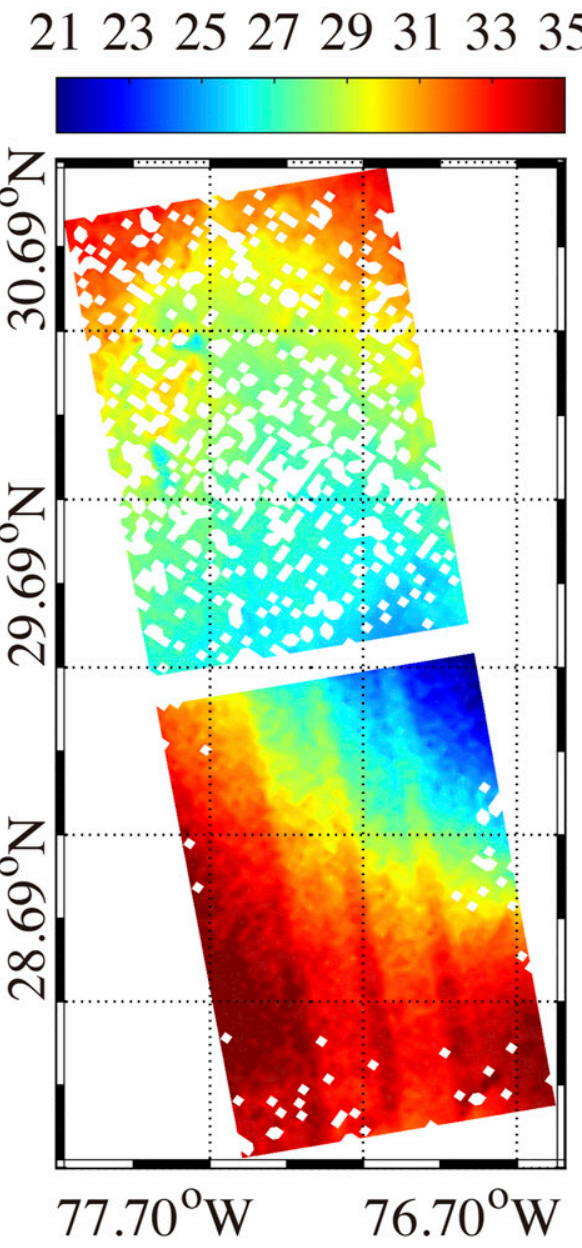

(a)

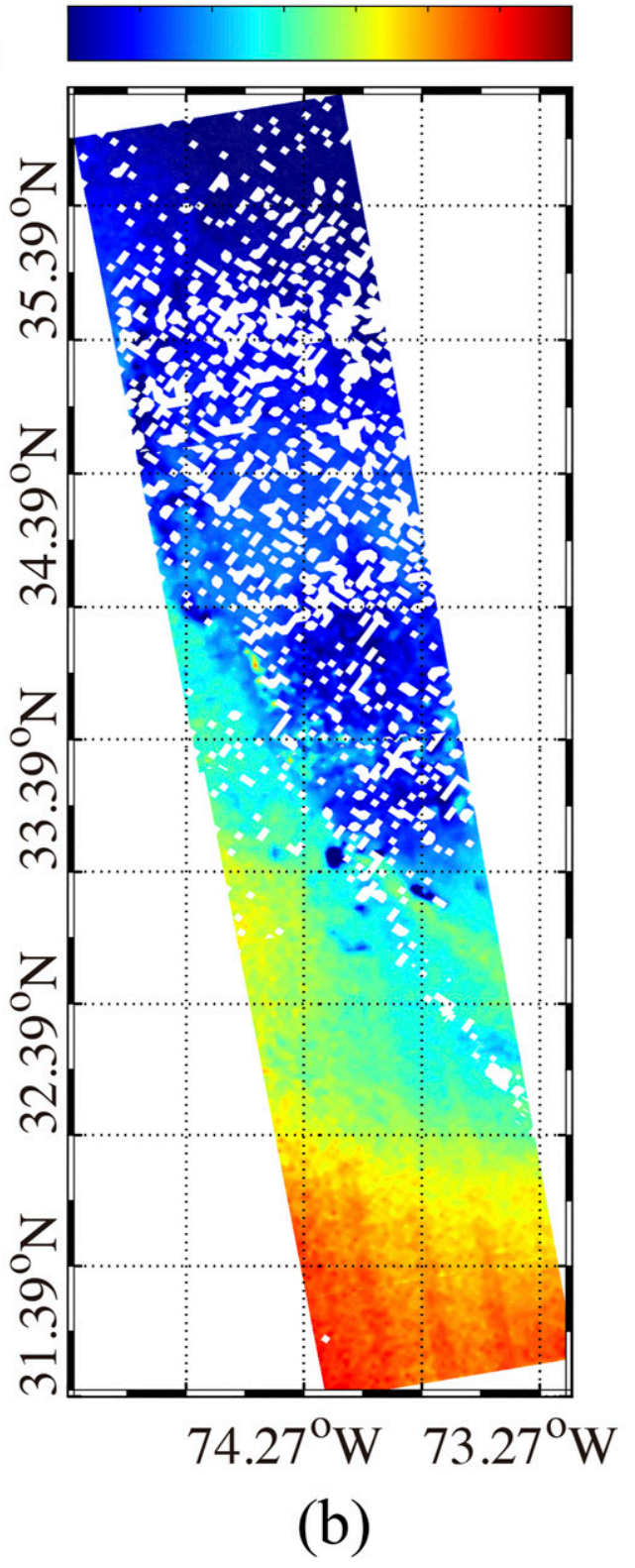

(b)

FIG. 14. Retrieval wind maps at (a) 2223 UTC 27 Oct and (b) 2249 UTC 28 Oct 2012 during Hurricane Sandy.

winds up to $35 \mathrm{~m} \mathrm{~s}^{-1}$. The average RMSE of the wind speed was $2.57 \mathrm{~m} \mathrm{~s}^{-1}$, with individual RMSE values of $3.37 \mathrm{~m} \mathrm{~s}^{-1}$ on 27 October and $2.08 \mathrm{~m} \mathrm{~s}^{-1}$ on 28 October. The overestimation of SAR-retrieved SWH at the sea state $H_{s}<4 \mathrm{~m}$ and this is the probable reason that the SAR-retrieved wind speeds are larger than those from HRD when wind speeds ranging from 15 to $25 \mathrm{~m} \mathrm{~s}^{-1}$. As shown in Fig. 16b, the wind speeds retrieved by proposed method for the case in Hurricane Miriam was contrasted with the wind speeds retrieved by GMF XMOD2. The larger RMSE $\left(=2.97 \mathrm{~m} \mathrm{~s}^{-1}\right)$ achieved in Fig. $16 \mathrm{~b}$ is probably caused by few data in the tune dataset at low sea state. Recently, Zhang and Perrie (2012) reported a comparison of wind retrieval using VV-and VH-polarization C-band SAR backscattering in hurricanes. The reference SFMR wind speed range was $2-38 \mathrm{~m} \mathrm{~s}^{-1}$, with the majority of data exceeding $20 \mathrm{~m} \mathrm{~s}^{-1}$. The RMSE ranged from 6.2 to $6.5 \mathrm{~m} \mathrm{~s}^{-1}$ for $\mathrm{VV}$ and from 3.2 to $4.5 \mathrm{~m} \mathrm{~s}^{-1}$ for $\mathrm{VH}$ polarization. Although the STD for $35 \mathrm{~m} \mathrm{~s}^{-1}$ winds was higher than that at $30 \mathrm{~m} \mathrm{~s}^{-1}$, we believe our approach is suitable for strong wind retrieval from $T S-X$ data in VV polarization, since 


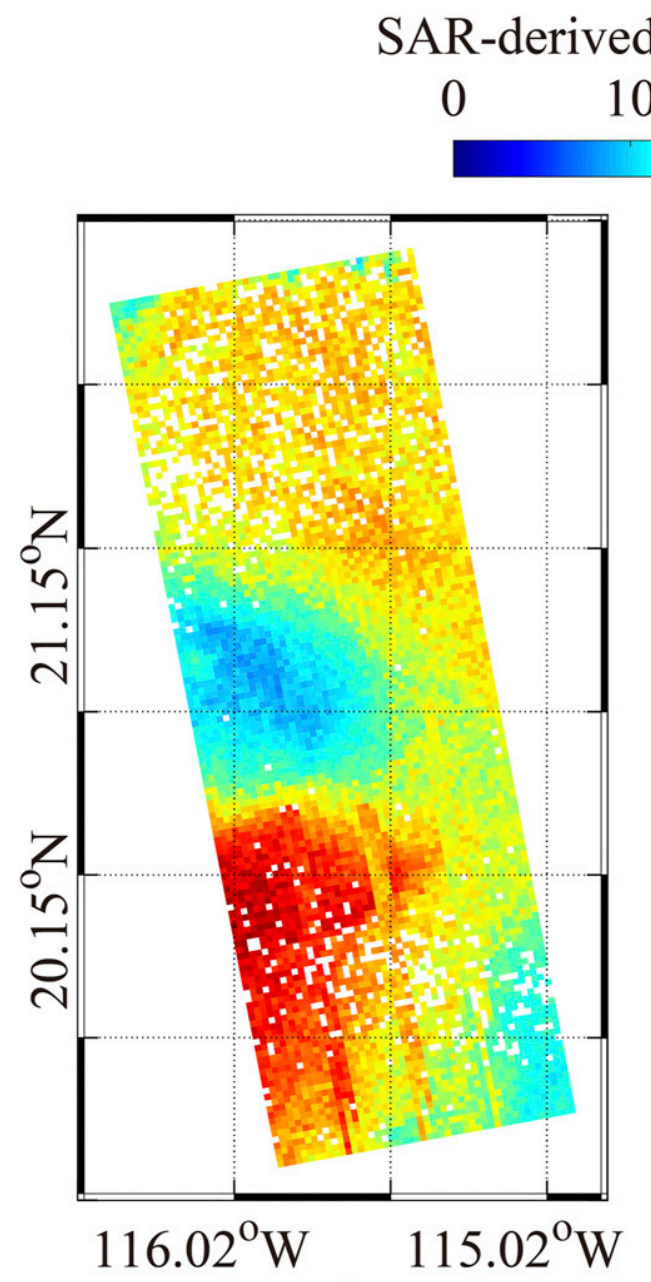

(a)

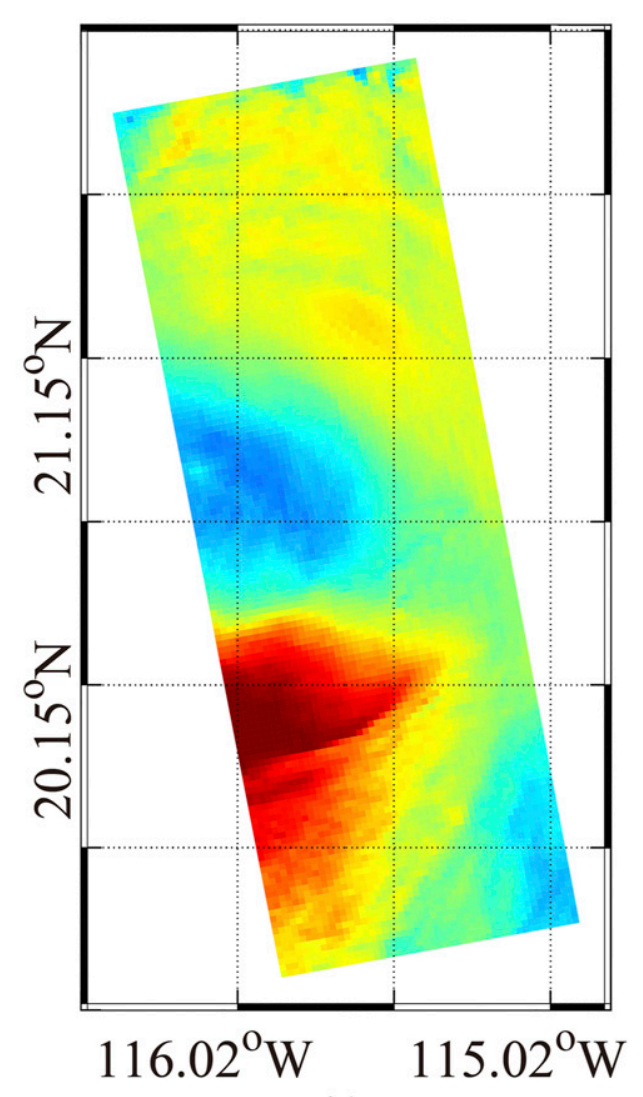

(b)

FIG. 15. Retrieval wind maps using (a) the proposed method and (b) using XMOD2. This case was taken at 0129 UTC 27 Sep 2012 during Hurricane Miriam.

the existing wind retrieval algorithm XMOD ( $\mathrm{Li}$ and Lehner 2014) is not applicable to typhoons and hurricanes.

\section{Discussion}

In this study, the integrity of the wind speed retrieval algorithm in cyclonic conditions was investigated. Unfortunately, the data matching with the HRD wind field at the left and back sides with respect to the cyclonic paths are collected, which is available for validating the SAR-derived wind speeds and lack of dataset to study the performance of XWAVE_TC at the right side of cyclonic paths. We further present the validation of fetch-based wind speeds at different sector of cyclones, as shown in Fig. 17a at left side $\left(\mathrm{RMSE}=2.59 \mathrm{~m} \mathrm{~s}^{-1}\right)$ and Fig. $17 \mathrm{~b}$ at back side $(\mathrm{RMSE}=$ $\left.2.52 \mathrm{~m} \mathrm{~s}^{-1}\right)$. The difference of the SAR-derived wind speeds with respect to the HRD wind speeds is plotted against the incidence angle from SAR images ranged from $30^{\circ}$ to $45^{\circ}$ in Fig. 18a. The difference of the SAR-derived wind speeds with respect to the HRD wind speeds is plotted against the wind speeds provided by the HRD in Fig. 18b. Note that the bin size is set to $1 \mathrm{~m} \mathrm{~s}^{-1}$ for wind speed. The error bars represent the standard deviation of each bin.

In general, the variation of the difference results (SARderived minus HRD wind speeds) was a linear function of the HRD wind speeds. The retrieved wind speeds exhibited a large deviation for light-to-moderate winds, i.e., the bias was $4 \mathrm{~m} \mathrm{~s}^{-1}$ for wind speeds $<17 \mathrm{~m} \mathrm{~s}^{-1}$; however, the bias likely decreases with increasing wind speed. Moreover, the difference was approximately $1.5 \mathrm{~m} \mathrm{~s}^{-1}$ for wind speeds $>25 \mathrm{~m} \mathrm{~s}^{-1}$. The underestimation was more likely caused by the time difference between the $T S$ - $X$ images and the HRD measurements. It is necessary to figure out that wind-wave triplet relations have a good performance at fully developed sea state, while the relations become weak at swells or crossseas sea state. Also, as pointed out in Shao et al. (2017b), the retrieval high wind speeds have large deviation at the back side of a tropical storm where wind-wave and swell are mixed. Alternately, the measurements from radar satellite 


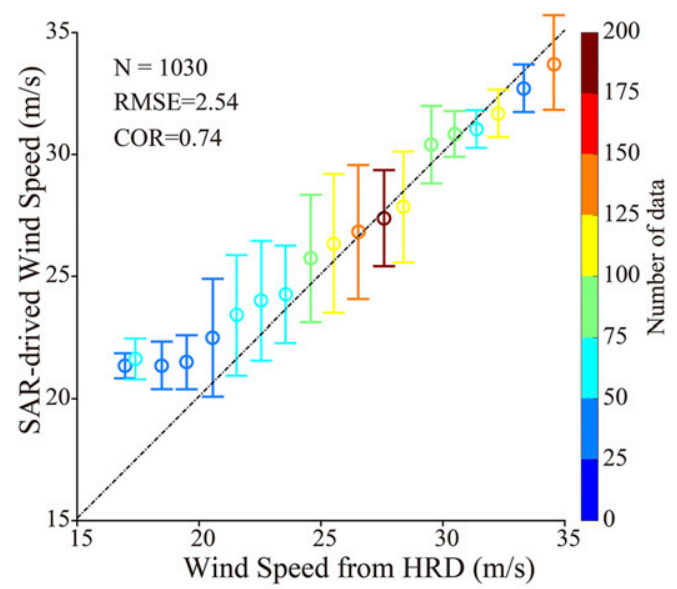

(a)

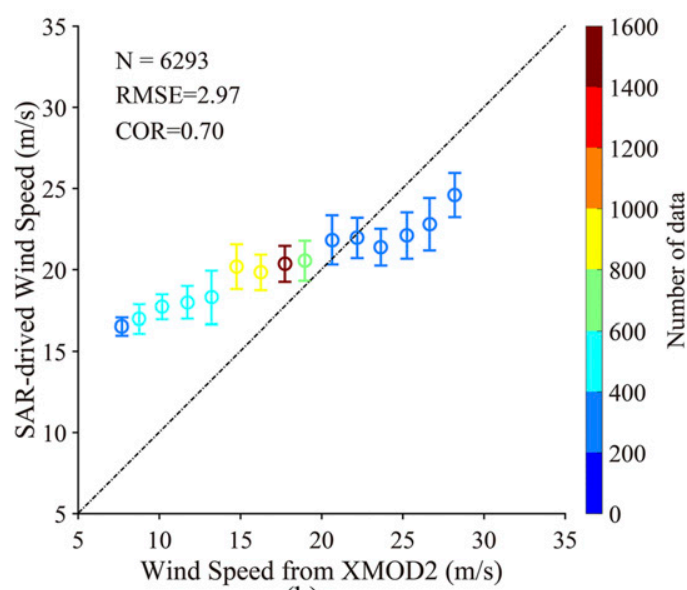

(b)

FIG. 16. SAR-derived wind speed contrasted with collocated measurements from (a) the HRD for a $1 \mathrm{~m} \mathrm{~s}^{-1}$ bin of wind speed and (b) XMOD2 for a $1.5 \mathrm{~m} \mathrm{~s}^{-1}$ bin of wind speed. The error bars represent the standard deviation of each bin.

observation is more accurate, e.g., altimeter and ChineseFrench Oceanic Satellite (CFOSAT).

\section{Conclusions}

Wind retrieval using the traditional SAR GMF has an RMSE of approximately $2 \mathrm{~m} \mathrm{~s}^{-1}$ when validated against measurements from in situ buoys or different scatterometers, although the wind speed range in the comparison datasets rarely exceeds $25 \mathrm{~m} \mathrm{~s}^{-1}$. Therefore, although X-band GMF XMODs have been developed for wind retrieval, they are not suitable for application in tropical cyclones. In particular, SAR data at cross-polarization channel are unavailable for $T S$ - $X$; therefore, there is no cross-polarization GMF for strong wind retrieval similar to that for C-band Sentinel-1 and $R A D A R S A T-2$ SAR. Based on fetch-limited wave development, a wave period $T_{p}$-based approach for strong wind retrieval within tropical cyclones has been developed. In particular, the updated fetch parameterization ensures uniform implementation in the different sectors of a cyclone. In this study, we applied the SWH $H_{s}$ retrieval technique for wind retrieval to $T S-X$ images taken of Typhoon Megi and Hurricane Sandy.

In this study, an approach for wind retrieval under extreme weather conditions was proposed that can be applied to $\mathrm{X}$-band SAR images collected by the German $T S-X$ mission. Since it relies on SWH, this approach does not exhibit the wellknown saturation phenomena that affects copolarized backscattering under extreme weather conditions. The collected

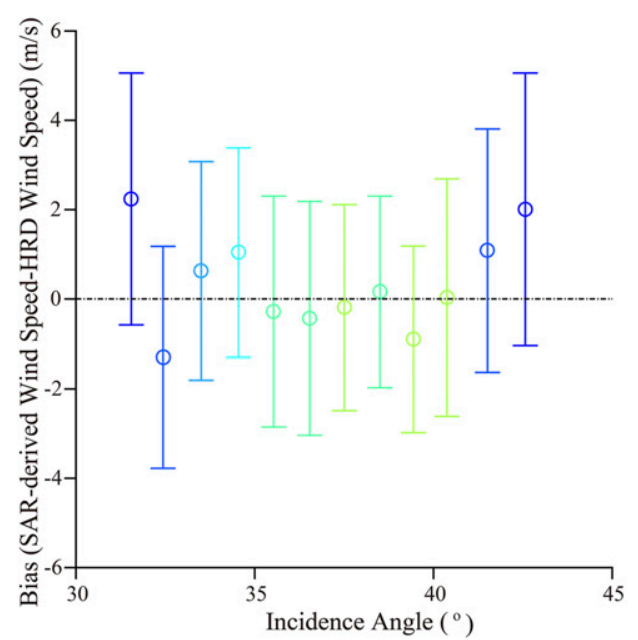

(a)

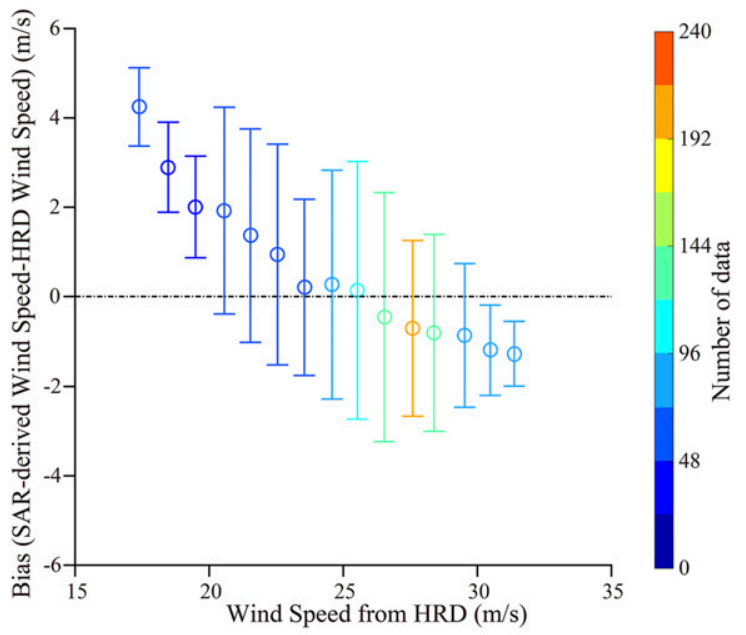

(b)

FIG. 18. Bias between SAR-derived wind speeds using the proposed algorithm and observed wind speeds from the HRD vs two parameters: (a) SAR incidence angles and (b) HRD wind speeds. 


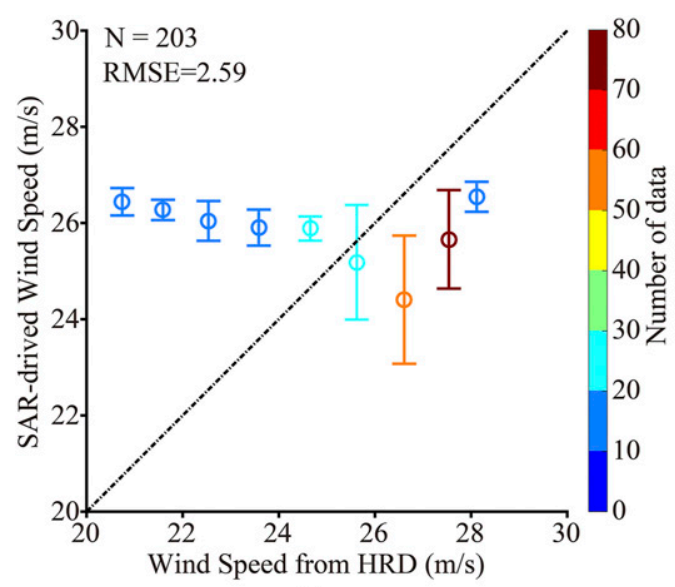

(a)

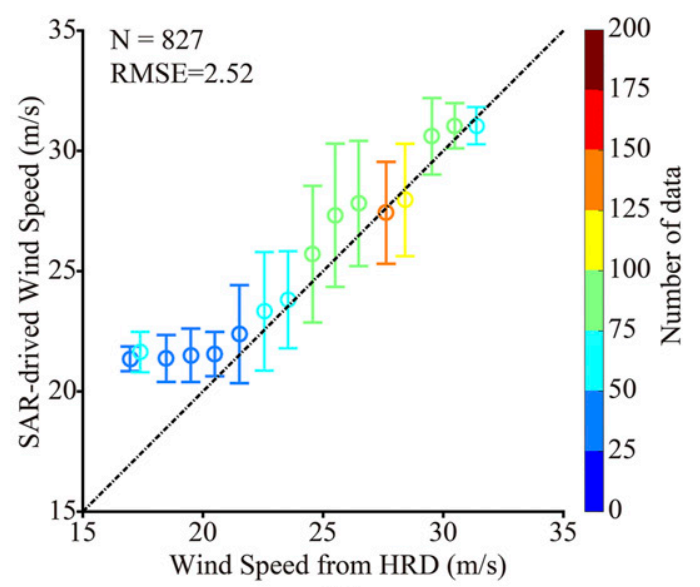

(b)

FIG. 17. SAR-derived wind speed contrasted with collocated measurements from the HRD for a $1 \mathrm{~m} \mathrm{~s}^{-1}$ bin of wind speed. The error bars represent the standard deviation of each bin. Comparison at (a) the left sides and (b) the back sides of cyclones.

$T S$ - $X$ images were collocated with simulations from the WW3 model, in which the maximum wind speed during the SAR acquisition was approximately $36 \mathrm{~m} \mathrm{~s}^{-1}$ and the range of SWH was up to $9 \mathrm{~m}$. However, the maximum wind speed is about $23 \mathrm{~m} \mathrm{~s}^{-1}$ with SWH up to $3 \mathrm{~m}$ for the case in Hurricane Miriam. We then updated a wave retrieval algorithm based on the CWAVE function for the X-band in cyclones, including the VV-polarized NRCS, azimuth cutoff wavelength normalized by the satellite range-to-velocity, normalized SAR intensity spectrum, peak SAR spectrum direction, homogeneity feature and incidence angle. A tuning phase for the empirical coefficients of the CWAVE function using a training dataset was performed and the retuned CWAVE model was denoted as XWAVE_TC. Analysis was carried out in order to investigate the performance of the retuned model for the SAR-simulated and WW3-simulated SWHs. This approach was demonstrated to provide consistent wind estimations that call for an RMSE of $2.54 \mathrm{~m} \mathrm{~s}^{-1}$ with respect to the NOAA HRD winds and an $2.97 \mathrm{~m} \mathrm{~s}^{-1}$ RMSE with respect to the retrieval results using GMF XMOD2.

It is concluded that the fetch-based wind retrieval algorithm is applicable to $T S-X$ data from typhoons and hurricanes, given it is due to a better performance for wind speeds $>20 \mathrm{~m} \mathrm{~s}^{-1}$ and lack of the saturation problem, although it still relies on a good-quality SAR intensity spectrum. We plan to assemble additional hurricane images for a more detailed analysis in future research, especially for demonstrating the robustness of fetch-based wind speed estimation algorithm at a strong hurricane or typhoon with Saffir-Simpson scale of more than category 3.

Acknowledgments. The authors acknowledge support from the National Natural Science Foundation of China under Grants 41806005 and 41776183, the China Postdoctoral Science Foundation under Contract 2020M670245, and the Science and Technology Project of Zhoushan City under Contract 2019C21008. The TerraSAR- $X$ images were acquired via the science AOs of
OCE2995 and OCE3150 provided by the German Aerospace Center (DLR). We appreciate the provision by the National Centers for Environmental Prediction (NCEP) of the National Oceanic and Atmospheric Administration (NOAA) of the source code for the WAVEWATCH-III (WW3) model supplied free of charge. The wave data from altimeter Jason-2 mission are accessed via https://data.nodc.noaa.gov. Sea surface current fields are open accessed via https://www.hycom.org. We also acknowledge and thank the European Centre for Medium-Range Weather Forecasts for providing reanalysis wind data at a $0.125^{\circ}$ grid, which can be openly downloaded from http://www.ecmwf.int.

\section{REFERENCES}

Alpers, W., and C. Bruning, 1986: On the relative importance of motion-related contributions to the SAR imaging mechanism of ocean surface waves. IEEE Trans. Geosci. Remote Sens., GE-24, 873-885, https://doi.org/10.1109/TGRS.1986.289702.

, D. B. Ross, and C. L. Rufenach, 1981: On the detectability of ocean surface waves by real and synthetic aperture radar. J. Geophys. Res., 86, 6481-6498, https://doi.org/10.1029/ JC086iC07p06481.

Badulin, S. I., A. V. Babanin, D. Resio, and V. E. Zakharov, 2007: Weakly turbulent laws of wind-wave growth. J. Fluid Mech., 591, 339-378, https://doi.org/10.1017/S0022112007008282.

Bruck, M., and S. Lehner, 2013: Coastal wave field extraction using TerraSAR-X data. J. Appl. Remote Sens., 7, 073694, https:// doi.org/10.1117/1.JRS.7.073694.

— , and - 2015: TerraSAR-X/TanDEM-X sea state measurements using the XWAVE algorithm. Int. J. Remote Sens., 36, 3890-3912, https://doi.org/10.1080/01431161.2015.1051630.

Buckreuss, S., and B. Schattler, 2010: The TerraSAR-X ground segment. IEEE Trans. Geosci. Remote Sens., 48, 623-632, https://doi.org/10.1109/TGRS.2009.2031432.

Corcione, V., F. Nunziata, and M. Migliaccio, 2018: Megi typhoon monitoring by $\mathrm{X}$-band synthetic aperture radar measurements. IEEE J. Oceanic Eng., 43, 184-194, https://doi.org/ 10.1109/JOE.2017.2700558.

- G. Grieco, M. Portabella, F. Nunziata, and M. Migliaccio, 2019: A novel Azimuth cutoff implementation to retrieve sea surface 
wind speed from SAR imagery. IEEE Trans. Geosci. Remote Sens., 57, 3331-3340, https://doi.org/10.1109/TGRS.2018.2883364.

Diaz Méndez, G. M., S. Lehner, F. J. Ocampo-Torres, X. M. Li, and S. Brusch, 2010: Wind and wave observations off the South Pacific coast of Mexico using TerraSAR-X imagery. Int. J. Remote Sens., 31, 4933-4955, https://doi.org/10.1080/ 01431161.2010.485217.

Hasselmann, K., and S. Hasselmann, 1991: On the nonlinear mapping of an ocean wave spectrum into a synthetic aperture radar image spectrum. J. Geophys. Res., 96, 10 713-10 729, https://doi.org/10.1029/91JC00302.

Hersbach, H., 2010: Comparison of C-band scatterometer CMOD5.N equivalent neutral winds with ECMWF. J. Atmos. Oceanic Technol., 27, 721-736, https://doi.org/10.1175/2009JTECHO698.1.

_- A. Stoffelen, and S. de Haan, 2007: An improved C-band scatterometer ocean geophysical model function: CMOD5.J. Geophys. Res., 112, C03006, https://doi.org/10.1029/2006JC003743.

Hu, Y. Y., W. Z. Shao, J. Shi, J. Sun, Q. Y. Ji, and L. N. Cai, 2020: Analysis of the typhoon wave distribution simulated in WAVEWATCH-III model in the context of Kuroshio and wind-induced current. J. Oceanol. Limnol, https://doi.org/ 10.1007/s00343-019-9133-6, in press.

Hwang, P. A., 2006: Duration- and fetch-limited growth functions of wind-generated waves parameterized with three different scaling wind velocities. J. Geophys. Res., 111, C02005, https:// doi.org/10.1029/2005JC003180.

_ 2016: Fetch- and duration-limited nature of surface wave growth inside tropical cyclones: With applications to air-sea exchange and remote sensing. J. Phys. Oceanogr., 46, 41-56, https://doi.org/10.1175/JPO-D-15-0173.1.

— growth of wind-generated ocean surface waves at young stage of development. J. Phys. Oceanogr., 34, 2316-2326, https://doi.org/ 10.1175/1520-0485(2004)034<2316:FMODGO>2.0.CO;2.

— B. B. Zhang, and W. Perrie, 2010a: Depolarized radar return for breaking wave measurement and hurricane wind retrieval. Geophys. Res. Lett., 37, L01604, https://doi.org/ 10.1029/2009GL041780.

,-- J. Toporkov, and W. Perrie, 2010b: Comparison of composite Bragg theory and quad-polarization radar backscatter from RADARSAT-2: With applications to wave breaking and high wind retrieval. J. Geophys. Res., 115, 246255, https://doi.org/10.1029/2010JC006653.

— , X. F. Li, and B. Zhang, 2017: Retrieving hurricane wind speed from dominant wave parameters. IEEE J. Sel. Top. Appl. Earth Obs. Remote Sens., 10, 2589-2598, https://doi.org/ 10.1109/JSTARS.2017.2650410.

Li, X. M., and S. Lehner, 2014: Algorithm for sea surface wind retrieval from TerraSAR-X and TanDEM-X data. IEEE Trans. Geosci. Remote Sens., 52, 2928-2939, https://doi.org/ 10.1109/TGRS.2013.2267780.

,-- , and T. Bruns, 2011: Ocean wave integral parameter measurements using Envisat ASAR wave mode data. IEEE Trans. Geosci. Remote Sens., 49, 115-174, https://doi.org/ 10.1109/TGRS.2010.2052364.

Liu, Q. X., A. V. Babanin, S. Zieger, I. R. Young, and C. L. Guan, 2016: Wind and wave climate in the Arctic Ocean as observed by altimeters. J. Climate, 29, 7957-7975, https:// doi.org/10.1175/JCLI-D-16-0219.1.

Mondon, E., and P. Warner, 2009: Synthesis of a validated nearshore operational wave database using the archived NOAA Wave Watch III ocean model data and SWAN nearshore model. J. Coastal Res., 45, 1015-1019.
Pleskachevsky, A. L., W. Rosenthal, and S. Lehner, 2016: Meteomarine parameters for highly variable environment in coastal regions from satellite radar images. ISPRS J. Photogramm. Remote Sens., 119, 464-484, https://doi.org/10.1016/j.isprsjprs.2016.02.001.

Quilfen, Y., A. Bentamy, T. Elfouhaily, K. Katsaros, and J. Tournadre, 1998: Observation of tropical cyclones by high-resolution scatterometry. J. Geophys. Res., 103, 7767-7786, https://doi.org/ 10.1029/97JC01911.

Ren, Y., S. Lehner, S. Brusch, X. Li, and M. He, 2012: An algorithm for the retrieval of sea surface wind fields using X-band TerraSAR-X data. Int. J. Remote Sens., 33, 7310-7336, https://doi.org/10.1080/01431161.2012.685977.

_, X. M. Li, and G. Zhou, 2015: Sea surface wind retrievals from SIR-C/X-SAR data: A revisit. Remote Sens., 7, 3548-3564, https://doi.org/10.3390/rs70403548.

Romeiser, R., H. C. Graber, M. J. Caruso, R. E. Jensen, D. T. Walker, and A. T. Cox, 2015: A new approach to ocean wave parameter estimates from C-band ScanSAR images. IEEE Trans. Geosci. Remote Sens., 53, 1320-1345, https://doi.org/ 10.1109/TGRS.2014.2337663.

Schulz-Stellenfleth, J., T. Konig, and S. Lehner, 2007: An empirical approach for the retrieval of integral ocean wave parameters from synthetic aperture radar data. J. Geophys. Res., 112, C03019, https://doi.org/10.1029/2006JC003970.

Shao, W. Z., X. M. Li, S. Lehner, and C. L. Guan, 2014: Development of polarization ratio model for sea surface wind field retrieval from TerraSAR-X HH polarization data. Int. J. Remote Sens., 35, 4046-4063, https://doi.org/10.1080/ 01431161.2014.916059.

_ X. F. Li, and J. Sun, 2015: Ocean wave parameters retrieval from TerraSAR-X images validated against buoy measurements and model results. Remote Sens., 7, 12815-12828, https://doi.org/10.3390/rs71012815.

_ Z Z. Zhang, X. M. Li, and W. L. Wang, 2016: Sea surface wind speed retrieval from TerraSAR-X $\mathrm{HH}$ polarization data using an improved polarization ratio model. IEEE J. Sel. Top. Appl. Earth Obs. Remote Sens., 9, 4991-4997, https:// doi.org/10.1109/JSTARS.2016.2590475.

, J. Wang, X. F. Li, and J. Sun, 2017a: An empirical algorithm for wave retrieval from co-polarization X-band SAR imagery. Remote Sens., 9, 711, https://doi.org/10.3390/rs9070711.

_ X. X. Fi, P. A. Hwang, B. Zhang, and X. F. Yang, 2017b: Bridging the gap between cyclone wind and wave by C-band SAR measurements. J. Geophys. Res. Oceans, 122, 6714-6724, https://doi.org/10.1002/2017JC012908.

— , Y. Y. Hu, J. S. Yang, F. Nunziata, J. Sun, H. Li, and J. C. Zuo, 2018a: An empirical algorithm to retrieve significant wave height from Sentinel-1 synthetic aperture radar imagery collected under cyclonic conditions. Remote Sens., 10, 1367, https://doi.org/10.3390/rs10091367.

_ , Y. X. Sheng, H. Li, J. Shi, Q. Y. Ji, W. Tan, and J. C. Zuo, 2018b: Analysis of wave distribution simulated by WAVEWATCH-III model in typhoons passing Beibu Gulf, China. Atmosphere, 9, 265, https://doi.org/10.3390/atmos9070265.

Sheng, Y. X., W. Z. Shao, S. Q. Li, Y. M. Zhang, H. W. Yang, and J. C. Zuo, 2019: Evaluation of typhoon waves simulated by WAVEWATCH-III model in shallow waters around Zhoushan Islands. J. Ocean Univ. China, 18, 365-375, https://doi.org/10.1007/s11802-019-3829-2.

Stoffelen, A., and D. Anderson, 1997: Scatterometer data interpretation: Estimation and validation of the transfer function CMOD4. J. Geophys. Res., 102, 5767-5780, https://doi.org/ 10.1029/96JC02860. 
_ J. Verspeek, J. Vogelzang, and A. Verhoef, 2017: The CMOD7 geophysical model function for ASCAT and ERS wind retrievals. IEEE J. Sel. Top. Appl. Earth Obs. Remote Sens., 10, 2123-2134, https://doi.org/10.1109/JSTARS.2017.2681806.

Stopa, J. E., F. Ardhuin, F. Collard, and B. Chapron, 2015: Estimating wave orbital velocities through the azimuth cut-off from space borne satellites. J. Geophys. Res. Oceans, 120, 7616-7634, https://doi.org/10.1002/2015JC011275.

Thompson, D. R., J. Horstmann, A. A. Mouche, N. S. Winstead, R. Sterner, and F. M. Monaldo, 2012: Comparison of highresolution wind fields extracted from TerraSAR-X SAR imagery with predictions from the WRF mesoscale model. J. Geophys. Res., 117, C02035, https://doi.org/10.1029/2011JC007526.

van Zadelhoff, G. J., A. Stoffelen, P. W. Vachon, J. Wolfe, J. Horstmann, and M. Belmonte Rivas, 2014: Retrieving hurricane wind speeds using cross-polarization C-band measurements. Atmos. Meas. Tech., 7, 437-449, https://doi.org/10.5194/amt-7-437-2014.
Voronovich, A., and V. Zavorotny, 2014: Full-polarization modeling of monostatic and bistatic radar scattering from a rough sea surface. IEEE Trans. Antennas Propag., 62, 1362-1371, https://doi.org/10.1109/TAP.2013.2295235.

Young, I. R., 1998: Observations of the spectra of hurricane generated waves. Ocean Eng., 25, 261-276, https://doi.org/ 10.1016/S0029-8018(97)00011-5.

_ 2006: Directional spectra of hurricane wind waves. Geophys. Res. Lett., 111, C08020, https://doi.org/10.1029/2006JC003540.

Zhang, B., and W. Perrie, 2012: Cross-polarized synthetic aperture radar: A new potential technique for hurricanes. Bull. Amer. Meteor. Soc., 93, 531-541, https://doi.org/10.1175/BAMS-D11-00001.1.

Zheng, K. W., J. Sun, C. L. Guan, and W. Z. Shao, 2016: Analysis of the global swell and wind-sea energy distribution using WAVEWATCH III. Adv. Meteor., 2016, 8419580, https:// doi.org/10.1155/2016/8419580. 